\section{Organizational Justice, Leader Humility, and Service Employees' Innovative Behavior in a Collectivistic Culture: The Case of Pakistan}

Wasim Abbas ${ }^{1}$

Weiwei $\mathrm{Wu}^{1}$

\section{Abstract}

Purpose - This study serves two purposes: first, it analyzes the effects of the overall perception of justice in service industry organizations on their employees' innovative behavior; second, it investigates whether leader humility moderates the relationship between the aforementioned constructs.

Design/methodology/approach - This study is quantitative in nature. A crosssectional survey method was used to collect data from 359 respondents, and a PROCESS macro for SPSS was used for the moderation analysis.

Findings - The results show that employees who perceive fairness within their organization will reciprocate with innovativeness and that humility is a positive factor that increases innovative behaviors.

Originality/value - Few studies have addressed the effect of the overall perception of justice on individuals' innovative behavior in service industries in developing economies and collectivist cultures. There is also a lack of empirical support regarding the role of leader humility in employees' innovative behavior. This study provides new insights into service employees' innovative behavior in a collectivist society and has implications for managers working in the services sector.

Keywords - justice; service employees' innovative behavior; leader humility; collectivist culture; developing economy

1. Harbin Institute of Technology, Department of Strategy and Innovation, Harbin, China

How to cite:

Abbas, W., Wu, W., (2021). Organizational Justice, Leader Humility, and Service Employees' Innovative Behavior in a Collectivistic Culture: The Case of Pakistan. Revista Brasileira de Gestão de Negócios, 23(1), p.153-179.
Received on:

06/12/2018

Approved on:

08/17/2020

Responsible Editor:

Prof. Dr. Jesús Barrena

Evaluation process:

Double Blind Review 


\section{Introduction}

Due to the fast-changing environment of recent years, organizations have been increasingly adopting and applying innovation (Li \& Hsu, 2016; Quintane, Casselman, Reiche, \& Nylund, 2011). In service industries, however, even though innovation is a key factor of firms' development and performance (Campo, Díaz, \& Yagüe, 2014), the rate of innovation in the sector lags behind that of manufacturing, where a lot more attention continues to be focused on research (Axtell et al., 2000; Li \& Hsu, 2016; Ramamoorthy, Flood, Slattery, \& Sardessai, 2005). Consequently, there have been calls for research on the key factors related to innovative behavior in service firms (Li \& Hsu, 2016; Sheehan, 2006).

Although a number of studies have investigated factors related to innovative behavior in services (Garg \& Dhar, 2017), the sector's importance to developing economies has received little attention despite the significant role it plays in economic growth (Thakur \& Hale, 2013). This study focuses on innovation in services in Pakistan, a developing economy (Ramírez-Pasilla, Brundin, \& Markowska, 2017). Pakistan's growing services sector has drawn attention in recent years, particularly with the construction of the China-Pakistan economic corridor (CPEC) (Ministry of Finance, 2018b). The most recent Pakistan Economic Survey (PES) reports that the services sector comprises the highest share of the country's gross domestic product and has experienced stable growth over the two-year period from 2016 to 2017 (Ministry of Finance, 2018a). In order to enhance or maintain a similar level of growth, the sector must improve its services through innovation. For this to occur, however, various supporting factors must be in place.

Innovative behavior in services may depend, in part, on perceptions of the exchange relationships within an organization (Young, 2012), where a benefit is conferred either in return for a comparable benefit received or for a benefit that is anticipated in the future. These exchange relationships may be economic or social in nature (Blau, 1964). For example, a relationship that consists of an economic exchange may be formal in nature and involve explicit legal sanctions; however, an exchange relationship that is social in nature may have unspecified returns, whether long term, intangible, or discretionary (Blau, 1964; Young, 2012). Exchange relationships within organizations could be developed through perceptions of organizational justice or the fair treatment of employees (Colquitt, Conlon, Wesson, Porter, $\&$ Ng, 2001; Cropanzano \& Rupp, 2008; Young, 2012).

Perceptions of organizational justice may serve as stimulants to exchange relationships (Akram, Haider, \& Feng, 2016a; Momeni, Ebrahimpour, \& Ajirloo, 2014) and have significant effects on work-related behaviors (Kerwin, Jordan, \& Turner, 2015). Folger and Cropanzano (1998) note that perceptions of positive or negative fairness result in positive or negative outcomes, respectively. Similarly, Jakopec and Sušanj (2014) point out that positive perceptions of fairness result in positive outcomes, whereas negative perceptions of fairness encourage destructive behaviors (Akram, et al., 2016a; Kerwin et al., 2015; Priesemuth, Arnaud, \& Schminke, 2013). Therefore, when employees perceive fairness in an organization, they exhibit innovative behavior in exchange.

Perceptions of organizational justice also differ across cultures (Chao \& Moon, 2005; Conner, 2003; Young, 2012). Individualistic societies tend to value justice more than collectivistic ones do (Mueller \& Wynn, 2000). Consequently, the relationship between organizational justice and innovative behavior has not been extensively studied in non-Western settings and this factor's generalizability to a collectivistic society remains underexplored (Young, 2012).

Shalley and Gilson (2004) note that innovation does not occur in isolation, but rather when personal and contextual characteristics interact (Wang, Zhang, \& Jia, 2017). In organizational settings, managers are traditionally the contextual factor and they usually decide on an idea's utility and innovativeness (Wang et al., 2017; Zhang \& Bartol, 2010). In recent years, research on leadership has drawn greater attention, particularly regarding the role managers play as leaders (Afsar, Badir, \& Saeed, 2014). Contemporary work settings are increasingly knowledge-based, so managers generally act as leaders who motivate employees to innovate (Afsar et al., 2014). Here, studies have focused on leadership styles and how these affect innovative behavior; however, leader humility as a leadership style that affects employee behavior has received little attention (Akram, Lei, \& Haider, 2016b; Judge, Fryxell, \& Dooley, 1997; Nusair, Ababneh, \& Bae, 2012), although some studies have discussed its importance (Gonçalves \& Brandão, 2017; Seijts, Crossan, \& Carleton, 2017).

Managers who demonstrate humility enable their organizations to become adaptable and develop the necessary continuous transformations required for their 
survival (Owens \& Hekman, 2012). Similarly, a leader or organization that does not possess humility as a virtue exhibits a crucial weakness (Vera \& Rodriguez-Lopez, 2004). One of the vital characteristics of humility is that those who demonstrate this trait encourage greater openness to experimenting (Owens \& Hekman, 2012). This allows individuals to openly discuss and develop new ideas that aim to achieve a competitive advantage for the organizations they work for (Gonçalves \& Brandão, 2017; Owens \& Hekman, 2012). Additionally, humble leaders permit the trials and errors that come with nurturing innovative behavior among individuals and groups (Gonçalves \& Brandão, 2017; Owens \& Hekman, 2012). However, as most of the literature on leader humility is theoretical (Owens \& Hekman, 2012), this construct lacks empirical support (Gonçalves \& Brandão, 2017). In particular, the effects of humble human interactions on individuals' innovative behavior remain obscure.

This research uses the lenses of social exchange theory (Blau, 1964) and signaling theory (Connelly, Certo, Ireland, \& Reutzel, 2010) to analyze the constructs of organizational justice, leader humility, and service employees' innovative behavior. These approaches see managers in organizations as signalers and employees as receivers. Managers signal which behaviors the organization values and rewards. If employees receive signals that their organization values certain behaviors, then they will tend to exhibit those behaviors. In return, they would expect positive reciprocal behavior from the organization, such as in a positive social exchange. Stinglhamber and Vandenberghe (2003) note that expectations of reciprocation may account for the achievement of organizational goals. When employees receive signals for open discussion, trial and error, and the development of new ideas, or if they perceive fairness and rewards, then they will reciprocate with innovative behavior.

In light of the above, this study has two objectives: first, it analyzes the effect of the overall perception of justice on service employees' innovative behavior and, second, it investigates whether leader humility moderates the relationship between the two aforementioned constructs. The results of our empirical study contribute to the literature in five ways. First, the study addresses the call for research on innovative behavior in service industries. Second, the findings redirect the focus of scholars from each type of perception to the overall perception of justice and open up avenues for understanding the relationship between the overall perception of justice and innovative behavior in service industries. Third, the study advances the literature on the interactional effect of leader humility. Fourth, it enhances the understanding of the role of leader humility in service innovation in the context of Pakistan, which is both a developing economy (Ramírez-Pasilla et al., 2017) and a collectivist country (Hofstede, 2018). Fifth, the study advances the understanding of organizational justice and leader humility in the context of both social exchange theory and signaling theory.

\section{Literature Review}

\section{I Service employees' innovative behavior}

Innovative behavior identifies a problem (Larson, 2011), generates ideas related to the problem, finds possible solutions (Janssen, 2000), and implements useful ideas by turning them into reality (Scott \& Bruce, 1994). Innovative behavior has been widely acknowledged in the literature and is considered a crucial resource in contemporary business environments. For example, innovative behavior enables organizations' long-term survival as it allows them to attain competitive advantages (Akram, Lei, Haider, \& Hussain, 2020). For organizations to encourage innovative behaviors, they must often rely on the innovation capabilities of individual employees (Castro \& Guimaraes, 2020). Employees' innovative behaviors are also categorized as positive deviant behaviors, since such behaviors enable individuals to deviate from existing norms and to challenge the status quo (creativity) (Wang, Liu, \& Zhu, 2018) to achieve desirable outcomes that favor the organization and its stakeholders, or both. This positive deviance is considered constructive deviance that is voluntary, discretionary, and extra-role behavior (Cohen \& Ehrlich, 2019).

Innovative behaviors in service industries include both employees and customers (Lee \& Hyun, 2016). On one side of the equation, employees are involved in identifying the problem, in the decision-making process regarding the problem, and in implementing a solution (Kesting \& Ulhøi, 2010); on the other side, customers cognitively ascertain whether the services delivered meet their needs and, if so, they generate loyalty to the service firm (Yuan \& Woodman, 2010). Service innovation may also help organizations achieve their goals and desired outcomes. For example, an innovation could eliminate obstacles to delivering a service by solving work-related problems (De Jong \& Den Hartog, 2010). It could also 
make organizational objectives attainable by improving service processes (Enz \& Siguaw, 2003). In addition, innovative behaviors in services contribute to increasing the quality of services, which could influence customers' decision-making and enhance their satisfaction ( $\mathrm{Li} \&$ $\mathrm{Hsu}, 2016)$. Moreover, innovative behaviors in services could help an organization maintain an edge over its competitors, by making it difficult to duplicate a service, for example, which could result in retaining a competitive advantage (Ottenbacher, 2007). Likewise, innovative behaviors in services could benefit organizations by helping them improve their core competencies and, thus, their organizational performance (Li \& Hsu, 2016). All of these factors point to the importance of innovative behaviors for service firms (Lee \& Hyun, 2016); however, this factor is often neglected or receives little attention among service organizations.

The literature on innovative behavior also discusses creativity and refers to both concepts as close cousins (Perry-Smith \& Mannucci, 2017). In most cases, the authors use both concepts interchangeably; however, they are distinct in nature (Li \& Hsu, 2016). Creativity occurs when an individual or a group working together in an organizational setting introduces, produces, or presents a unique, novel, or useful idea; whereas innovation not only includes introducing a new or distinct idea but also implements the new idea within the context of the organization (Amabile \& Pratt, 2016). A number of theorists explain the distinct nature and importance of each of these constructs. For example, scholars of creativity emphasize the generation of novel ideas, while scholars of innovation point to implementation as the primarily focus of the construct (Perry-Smith \& Mannucci, 2017). Since the generation of a novel idea (creativity) must occur before it can be implemented (innovation), several scholars consider creativity as a precondition for innovation (Lukes \& Stephan, 2017). Similarly, Schilling (2008) presents creativity as an antecedent of innovation; Ghosh (2015) discusses creativity as a prerequisite and starting point of innovation; and Oldham and Cummings (1996) consider creativity as a force that causes innovation. Consequently, innovative behavior is said to be an outward expression, one that extends to the final output and that produces actual benefits; thus, it constitutes both the generation and application of novel ideas (Larson, 2011; Li \& Hsu, 2016).

Scott and Bruce (1994) were the first to conceptualize the idea of service employees' innovative behaviors. Subsequently, different authors have provided some modifications to this concept (Hu, Horng, \& Sun, 2009; Lee \& Hyun, 2016). Kim and Lee (2013) note that service employees' innovative behaviors (SEIB) can lie in the accumulation of new ideas whose aim is to address problems identified in the repeated failure of a service or services and the special treatment thereof. Similarly, Hu et al. (2009) note that SEIB can occur in the development of new service techniques, methods, and skills whose aim is to address service failures or to search for new avenues through which to provide a service. Hence, the extant literature discusses SEIB within two streams: (1) in resolving problems identified in services (i.e., repeated service failures) and (2) in introducing new methods, techniques, and skills to minimize or mitigate potential services failures. Each stream focuses on the provision of high-quality services to enhance the customer experience and the level of satisfaction within the services sector. Consequently, we define employees' innovative behaviors in the services sector as intentional behaviors that generate and implement creative ideas that lead to the introduction of the novel processes, procedures, services, techniques, methods, and skills that help elevate the quality of services (existing and future), and raise the customers' experiences and satisfaction to the next level.

This study conceptualizes SEIB at the individual level as intentional behaviors that introduce new processes, new ways of working, and new services ( $\mathrm{Hu}$, et al., 2009; Lee \& Hyun, 2016) through idea generation and implementation (Scott \& Bruce, 1994).

\subsection{Organizational justice}

Organizational justice has received some attention in the field of organizational behavior, and researchers have validated its importance in the literature (Akram, et al., 2016a; Spell \& Arnold, 2007). Organizational justice is defined as employees' perceptions of fairness within an organization (Greenberg, 1987). The three-dimensional model of organizational justice has been extensively studied, and it includes distributive, procedural, and interactional justice (Aguiar-Quintana, Araujo-Cabrera, \& Park, 2020; Demir, Guney, Akyurek, Ugural, \& Aslan, 2017; Hsu \& Wang, 2015; Kerwin et al., 2015). The literature also includes a four-dimensional model that subcategorizes interactional justice into informational and interpersonal justice (Colquitt, et al., 2001; Greenberg, 1990;). There is also a five-dimensional model that identifies both temporal and spatial justice as new additional dimensions 
that supplement the earlier three-dimensional model (Akram et al., 2020). The literature often divides the concept of organizational justice into various types of justice and more finely defines it; for example, type one: distributive; type two: distributive and procedural; type three: distributive, procedural, and interactional; type four: distributive, procedural, informational, and interpersonal; and type five: distributive, procedural, interactional, temporal, and spatial (Akram, et al., 2020; Greenberg \& Colquitt, 2013).

In addition to the different types of justice, researchers have also studied the overall perception of justice within an organization (Abbas \& Wu, 2019a; Ambrose \& Schminke, 2009). Some even question the merit of focusing on specific types of justice and suggest only considering the overall level of justice (Ambrose \& Arnaud, 2005; Cropanzano \& Ambrose, 2001; Mohammad, Quoquab, Makhbul, \& Ramayah, 2016). Some scholars note that the overall perception of justice provides a clearer and better understanding of justice within an organization (Abbas \& Wu, 2019a; Mohammad, et al., 2016). This is because, in the case of injustice, employees generally share the same experience and are unlikely to worry about the different types (two, three, four, or five) of justice (Shapiro, 2001). Therefore, following the latter convention, this study considers organizational justice as the overall perception of justice, which is a unidimensional construct that defines individuals' perceptions regarding the overall fairness within an organization as a whole (Abbas \& Wu, 2019a; Mohammad, et al., 2016)

\subsection{Leader humility}

Humility is a complex construct (Morris, Brotheridge, \& Urbanski, 2005) that not only includes different facets of behaviors but also behavioral tendencies (Gonçalves \& Brandão, 2017). Humility enables one to have an honest understanding of one's strengths and weaknesses; therefore, it can be thought of as the science of the self (Comte-Sponville, 2002). Similarly, humble people have the ability to self-exam, avoid being self-centered, and are well aware of their limits (Emmons, 2000; Rowatt et al., 2006). Additionally, humility means being able to assess one's abilities and achievements within a given context (Richards, 1992). Humble people are able to more accurately assess not only their own characteristics but also the abilities of others (Peters, Rowat, \& Johnson, 2011). In personality psychology, humility is considered a stable, positive, and enduring human trait that is influenced by situational factors (Peterson \& Seligman, 2004; Tangney, 2000). Thus, humility is a virtue, it varies according to the situation, and a meta-attitude can develop (Owens, Rowatt, \& Wilkins, 2012). Owens and Hekman (2012) examined and built the theory of leader humility. According to the authors, the three dimensions of humility are admitting personal mistakes, faults, and limits; understanding the strengths, weaknesses, and contributions of followers; and exhibiting teachability (Gonçalves \& Brandáo, 2017; Mao, Chiu, Owens, Brown, \& Liao, 2019). Leader humility significantly raises employee satisfaction, loyalty, and trust; it also supports psychological freedom. Consequently, followers of humble leaders become confident, feel free to experiment using their own approaches, and contribute to solving future problems (Nielsen \& Marrone, 2018; Owens \& Hekman, 2012).

The concept of leader humility has been an area of interest to many researchers and practitioners (Luu, 2020; X. Wang, Li, \& Yin, (in press); Yang, Zhou, Wang, Lin, \& Luo, 2019) who have studied humility in a range of disciplines, such as organizational behavior and positive psychology at the team and organizational levels (Nielsen \& Marrone, 2018). These researchers also argue that the interdependent and relational nature of business and leadership cannot be neglected; they posit that humility in leadership is crucial for organizations as it facilitates the achievement of positive outcomes at the individual, team, and organizational levels (Wang et al., in press). For example, in their study on humility, Wang et al. (in press) investigated 104 teams within five heterogeneous organizations in China. They found that humility among leaders encourages creativity at the team level through collective creative efficacy. Similarly, Luu (2020) analyzed humility among sales managers, using samples from two companies in Vietnam: a telecommunications company and a computer company. The study concluded that there is a significant, direct, and positive relationship between humility among sales managers and adaptive selling among their sales teams. Likewise, Yang et al. (2019) studied leader humility, using samples from the healthcare sector in China. They found that humility among leaders in healthcare is significantly and positively related to engagement and innovative behaviors among nurses.

Since there are few empirical studies on leader humility (Rego et al., 2017; Wang et al., 2017), its interactional effect also generally remains unexplored. Consequently, this study 
conceptualizes leader humility as a virtue (Owens et al., 2012) and analyzes its interactional effects.

\subsection{Collectivist versus individualistic cultures}

Culture differentiates members of one society from those of another; it is based on the shared beliefs, behaviors, and values of the individuals in a particular social group (Hofstede, 1991). Additionally, considering shared behaviors, Hofstede (2001) divides cultures into collectivism and individualism. Collectivist cultures value groups, whereas individualistic cultures value individuals (Hofstede, 2001). In collectivist cultures people consider themselves as part of a whole where the emphasis is on group membership and preferences remain integrated into family structures and prioritize group interests over personal ones (Triandis, 2001; Van Hoorn, 2015). In contrast, in individualistic cultures people prefer to only take care of themselves (e.g., by pursuing their own personal rights and goals) and their immediate family members (Van Hoorn, 2015). Likewise, cooperation and group harmony are more important in collectivist cultures, whereas in individualist cultures the emphasis is on uniqueness and autonomy (Noon \& Lewis, 1992). In line with the different approaches to fairness in different cultures, merit-based equity is considered fairer in individualistic cultures (Murphy-Berman \& Berman, 2002). Extending this to experiences in the workplace, organizations in individualistic cultures place greater value on justice than those in collectivistic cultures (Mueller \& Wynn, 2000). In collectivist cultures emotions are contextualized to interact within the group and also to enhance group harmony; whereas in individualistic cultures emotions are considered an individual right and the expression of emotion is encouraged. Therefore, in collectivist cultures emotions are managed, while individualistic cultures emphasize emotional expression (Allen, Diefendorff, \& $\mathrm{Ma}, 2014)$. Moreover, there are stark differences between how emotional ties are considered in each of these two types of cultures. In collectivist cultures emotional ties are highly valued for maintaining group cohesion; however, this is not considered as important in individualistic cultures. Additionally, in a collectivist culture leaders are highly valued for maintaining emotional ties and relationships with group members (Javidan, Dorfman, Luque, \& House, 2006).

The national culture of Pakistan is considered collectivistic due to its unique characteristics. In Pakistan, family ties are strong, a sense of collective interest remains intact and people like spending time together (Kashif \& Khattak, 2017). In fact, all major life decisions are taken by seeking the consensus of all concerned. In general, decisions over buying a home, admission to a university, choosing a career, getting married, and medical treatments take into account the views and opinions of family members. In concurrence with Hofstede's (2001) cross-cultural research, for people in Pakistan, the collective good takes precedence over pursuing individual interests. Similarly, Kim, Chung, and Suh (2016) note that collectivist values are also reflected in Pakistan's collectivist culture; i.e., people emphasize social relatedness, social roles, collective interests, and obligations to others. Pakistan's collectivist orientation is also reflective of the collectivist values highlighted by Minkov et al. (2017); i.e., its people strive to maintain harmony, achieve a high degree of group integration, discourage divergence from traditions, and emphasize interdependence. The collectivist mindset that guides decision-making in private life also influences decision-making in organizational life. For example, the behavioral intentions of employees working in Pakistan's service organizations (e.g., fast food chains) are influenced by subjective norms (Kashif \& Khattak, 2017). Similarly, unlike in individualist societies, in Pakistan's service organizations, employees maintain strong intergroup relationships, have tight social networks, and strictly comply with group decisions (Bashir, Khattak, Hanif, \& Chohan, 2011). Therefore, the aforementioned national cultural characteristics categorize Pakistan as a collectivist society where collectivism influences people's personal and professional lives.

\subsection{Model and hypotheses development}

Innovative work is the result of the individual, discretionary, voluntary, and extra-role behaviors that come from motivational drive (Akram et al., 2016a). Janssen (2000) notes that organizational justice may serve as the motivational factor behind individuals' innovative behaviors. Additionally, he also notes that organizational justice may have positive or negative effects on employees' behaviors. For example, feelings of having been unfairly treated may lead to a decline in performance and less contribution to work (Momeni et al., 2014). Numerous studies have investigated the relationship between organizational justice and innovative behaviors. However, according to some researchers (Akram et al., 2016a; Hsu \& Wang, 2015; 
Khaola \& Coldwell, 2019; Young, 2012), no single study has considered the overall aspect of organizational justice and its effect on employees' innovative behaviors in the services sector in Pakistan.

Akram et al. (2016a) conducted research on telecommunications in China and found significant relationships between the types of justice and innovative behaviors. Similarly, Hsu and Wang (2015) conducted a mediation analysis, using organizational support, and found a positive correlation between organizational justice and innovative work behaviors, in that the higher the level of justice, the greater the innovative behavior. Likewise, Demir et al. (2017) also found that employees' perceptions of organizational justice boost their confidence and satisfaction levels. Along the same lines, more recently, Akram et al. (2020) conducted mediation analyses, using knowledge sharing, and found that employees' perceptions of organizational justice have positive and significant impacts on innovative work behaviors. Therefore, this study proposes its first hypothesis, as follows:

Hypothesis 1: Organizational justice has a positive effect on employees' innovative behaviors in the service industry.

The relationship between managers and employees has been substantially discussed in the literature (Morris et al., 2005). Particular importance has been given to managers' supportive behaviors toward employees (Hofstede, Bond, \& Luk, 1993; Mariappanadar, 2018; Seers, McGee, Serey, \& Graen, 1983; Teoh, Coyne, Devonish, Leather, \& Zarola, 2016; Yiing, \& Ahmad, 2009). For instance, when employees perceive that their leader is supportive, their work participation increases (Janssen, 2005). Similarly, Chao, Lin, Cheng, and Tseng (2011) found a positive relationship between a supervisor's leadership and employees' innovative behaviors. Nevertheless, the research on the effect of leadership on innovative behaviors is limited (Akram et al., 2016a; Noor \& Dzulkifli, 2013). In particular, little attention has been given to leader behavior (i.e., humility) and its effect on innovativeness (Akram et al., 2016a; Mumford, 2003). Although both variables - organizational justice and leader humilitydirectly affect innovative behaviors, the literature on their interactional effect is sparse. This paper argues that the interactional effect of leader behavior enhances innovative behavior in services. However, although the organizational factor (i.e., organizational justice) may allow employees to pursue innovative behaviors, these people are rarely able to implement ideas on their own
(Lukes \& Stephan, 2017). Here, leadership plays an important role in helping employees implement their ideas (Binnewies, Ohly, \& Sonnentag, 2007). Humble leaders, through their behaviors, facilitate employees' discussions of ideas and this fosters creativity and leads to the implementation of novel ideas (Wang, et al., 2018; Zhou \& Wu, 2018). Leaders with high levels of humility avoid disrespectful behaviors and are more likely to avoid competition with others (Richards, 1992). Similarly, they avoid taking a superior stance during communications with their employees and, instead, adopt egalitarianism (Morris et al., 2005). Consequently, we argue that the interaction between organizational justice and leader humility is more likely to enhance innovative behaviors among employees by forming supportive relationships. Along the same lines, Lee, Gizzarone, and Ashton (2003) also found an inverse relationship between exploitative behaviors and honesty/humility. They found that individuals who score higher on honesty/humility scales are less likely to harm others. Therefore, this study predicts that leaders with high humility tend to increase innovative behaviors in the services sector.

Hypothesis 2: Leader humility moderates the positive relationship between organizational justice and employees' innovative behaviors in services, such that this positive relationship will be stronger with higher levels of leader humility.

Here, social exchange theory (Blau, 1964) and signaling theory (Connelly et al., 2010) are used as theoretical lenses through which to understand the relationship between the variables. The tenets of social exchange theory explain that the "reciprocal exchange quality" influences the socialization and psychological connectedness (Grace, King, \& Lo Iacono, 2017). In essence, the theory weighs the potential benefits of these social relationships against their costs and risks. Similarly, the relationship between different entities, such as customers, employees, and managers, can also be analyzed along the lines of this theory. For example, the leader-member exchange and the coworker exchange are positively related to customer service (Kim \& Qu, 2020). In addition, social exchange theory is also utilized to explain how important organizational resources influence employee engagement (Cooper-Thomas, Xu, \& Saks, 2018). In the organizational context, employees have different types of knowledge and expertise, which they can leverage to bring about creativity and innovation. Their contributions to the organization come in the form of their novel ideas, 
methods, and techniques. However, these factors will only flourish and develop under certain conditions, i.e., when employees perceive equity and justice within the organization. If employees perceive that they are being treated fairly in all aspects of their employment, then they may reciprocate with novel ideas. On the contrary, if employees perceive that they are not being treated fairly in major aspects of their organizational life, then they may reciprocate with lower or no motivation for making creative contributions.

Although signaling theory was initially proposed on the basis of observed knowledge gaps between organizations and their prospective employees (Spence, 1973), the theory was later adapted to many other fields, such as human resources management, business, and financial markets (Connelly, et al., 2010). In the organizational context, the theory postulates that managers send signals to their employees through their actions and behaviors. A manager's actions represent what they value most for leadership and what actions are rewarded or punished. The theory also states that a leader's behavior that is conducive to and signals support for employees' creativity is based on humility. When employees perceive that their leader is humble and also recognizes their skills, values, knowledge, and strengths, their confidence in relation to trying out novel ideas may accelerate. Similarly, a leader's behavior that embraces openness to learn from others and to seek or accept advice may also be conducive to their employees' creative behaviors. Therefore, in the case of this research, based on social exchange theory and signaling theory, we contend that when employees perceive fairness within an organization, they reciprocate with discretionary behaviors and humility_-positive signals that escalate their innovative behaviors.

In the overall research framework, regulatory fit theory can be used to explain how all of the hypotheses in this study can be integrated (Higgins, 2005). The theory posits that people get involved in activities for which they "feel right" and believe there is a "fit" (Higgins, 2005). The term "fit," or regulatory fit, is a subjective evaluation of a persuasive message (verbal or non-verbal) that determines the recipients' reactions (positive or negative) (Cesario, Grant, \& Higgins, 2004; Cesario, Higgins, \& Scholer, 2008). For example, Schwarz and Clore (1983) found that recipients infer a message positively when they feel right about it, and vice versa. Extending this assumption to service enterprises, this study predicts that the overall perception of justice will serve as a positive non-verbal message coming from the organization and that this will be reciprocated in a positive manner, such as in performing an extra-role behavior. In addition, the regulatory fit is also referred to as a motivational experience (Kruglanski, Pierro, \& Higgins, 2007) that may consist of interpersonal determinants. For instance, Kruglanski et al. (2007) highlight the role of supervisors, teachers, and parents (people with power) in persuading their subordinates, students, and children, respectively, to perform activities and maintain a regular fit. In a similar manner, this paper predicts that humble leaders, through their behaviors (a non-verbal signal), can persuade their subordinates to embrace innovative behaviors and implement novel ideas. Furthermore, the literature on regulatory fit theory also suggests that when identical messages come from different sources this has a greater impact on participants (Cesario et al., 2004), meaning that similar positive messages from different sources send strong positive signals and yield favorable results in greater returns. Extending this concept to the services scenario, the current study also predicts that the interactional effect between overall justice and leader humility will foster innovative behaviors in a different way to either overall justice or leader humility alone. Figure 1 shows the framework of the study.

\section{Research Methodology}

This study is quantitative in nature and uses the cross-sectional survey method, using Google forms to collect the data. The potential respondents were individuals enrolled in an executive master of business administration program, where professionals can study at business schools in Karachi while continuing to work full time.

Prior to contacting the respondents, the author sought permission from the relevant authorities to collect the necessary data (i.e., program managers, course instructors, and coordinators). Next, a session was arranged for the respondents in which the researcher presented the purpose of the research and addressed concerns over confidentiality and anonymity. The researcher then asked the respondents who were willing to participate to provide their functional email addresses. A total of 431 email addresses were collected. In the following week, an email was sent out to these participants. It included the purpose of the research, a statement of confidentiality and anonymity, and instructions on how to access the survey questionnaire, via a secure link, and how to complete it. 


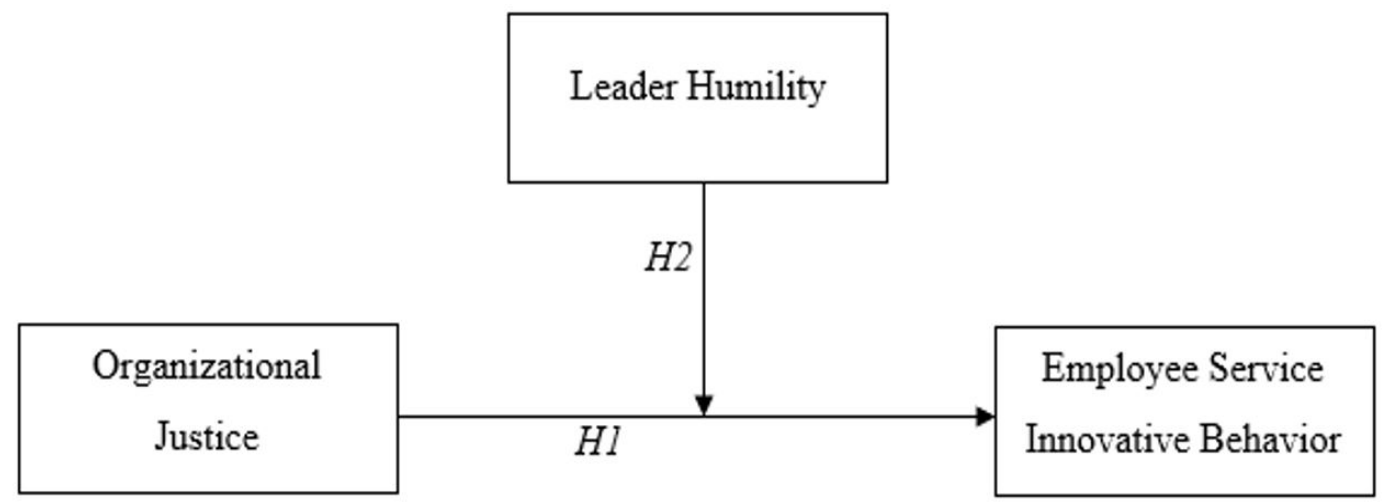

Figure 1. Framework of the study

The participants were given one month to respond and courtesy reminders were sent out on the $13^{\text {th }}$ and $26^{\text {th }}$ days of the survey. During the specified time period, we received 380 responses, representing a response rate of $88.16 \%$ (380/431). Respondents were excluded if they (1) were not full-time employees; (2) were self-employed; (3) were working in a family-owned business; (4) were not employed in the services sector; or (5) failed to submit a complete dataset, as these respondents may have negatively influenced the results. The final usable dataset consisted of responses from 359 participants, of whom 59\% were male, 53.4\% were between 30 and 34 years of age, and $76.6 \%$ were married. Subsequently, a power analysis was conducted using the software package $\mathrm{G}^{*}$ Power (Faul, Erdfelder, Buchner, \& Lang, 2009). The power analysis showed that the sample size was more than adequate for a moderate to large size effect, considering the input parameters $f^{2}=0.15$ (medium size effect), $p<0.05$, power of the statistical test $=0.95$ (whereas 0.80 is the traditional power), and the predictors $=3$ (J. Cohen, 1977). Table 1 presents the respondents' profiles.

The e-questionnaire comprised questions on 25 items, divided into four sections, marked as A, B, C, and D, respectively. There were five questions on demographics and five on SEIB, which were adapted from Hu et al. (2009); the six questions on organizational justice (considered as unidimensional) were adapted from Ambrose $\&$ Schminke (2009); and the nine on leader humility were adapted from Owens, Johnson, \& Mitchell (2013). All items used for SEIB, organizational justice, and leader humility had been previously validated and recently employed by Lee and Hyun (2016), Mohammad et al. (2016), and Gonçalves and Brandão (2017), respectively. A five-point Likert scale was used, ranging from $1=$ strongly disagree to $5=$ strongly
Table 1

Respondents profiles

\begin{tabular}{lccc}
\hline & & N & Percentage (\%) \\
\hline Gender & Males & 212 & 59.05 \\
& Females & 147 & 40.94 \\
Age group & $25-29$ & 125 & 34.81 \\
& $30-34$ & 192 & 53.48 \\
& $35-39$ & 37 & 10.30 \\
\multirow{4}{*}{ Marital status } & $40-44$ & 5 & 1.39 \\
& Married & 275 & 76.60 \\
& Unmarried & 84 & 23.39 \\
\hline
\end{tabular}

agree, for all measures. None of the items were tagged with an asterisk (mandatory to answer) except for the description section, which comprised the purpose of the research, a statement of confidentiality and anonymity, instructions on how to complete the questionnaire, and a statement that the participant was involved in the study of their own free will on a voluntary basis. The purpose of not tagging any item with an asterisk was to maintain the respondents' free will at each stage. Also, to address ethical concerns, for the description section it was considered necessary to mark the questions as mandatory. The research instrument was finalized in consultations with two academics and three industry experts. Appendix shows the item codings and items for each variable used in this study. In light of the consultations, minor language changes were made and a pilot test was conducted. Based on the results of the pilot test, the questionnaires were adjusted and then disseminated. The purpose of the pilot study was to improve the quality and efficiency of the principal study. In line with this purpose, we conducted an initial pilot study to analyze the following: (1) the challenges in collecting emails and sending the survey links; (2) the refusal rate; (3) the 
respondents' ability to comprehend the instructions in the cover letter; (4) the respondents' understanding of the terminology used, the questionnaire items, and the flow and sequence of the statements; (5) our understanding of the respondents' responses (i.e., no response, multiple response, or incomplete survey); (6) the response times (i.e., the time respondents took to answer the survey email); (7) the time taken to fill out the questionnaire; (8) the respondents' difficulties in terms of understanding the confidentiality and anonymity aspects of the study; (9) the language comprehension rate; and (10) the respondents' supplementary comments (if any). The participants in this pilot study were professionals employed in the services sector. A special session was arranged to present the purpose and objectives of the research and the pilot study, respectively. Later, emails were collected from the participants who volunteered. The survey participants for the pilot study had a minimum of three years of job experience. Three years of experience meant these respondents could provide important insights into the different aspects of decisionmaking at their organizations. This level of experience also meant that the respondents were fairly conversant with organizational practices and how much their organization valued organizational justice and leadership support. Moreover, these respondents came from a variety of service industries, making it easier to generalize the results. At the end of the session, 45 respondents volunteered and emails were sent to their given addresses. The analysis of their responses did not indicate any major problems related to the e-questionnaire; however, minor language changes to a few items were recommended. Therefore, these amendments were added to final the questionnaire so as to increase the comprehension of the questionnaire items in the study's survey.

\section{Data Analysis}

First, the data were screened to detect any multivariate outliers; here, we calculated the Mahalanobis distance, the leverage, and the Cook's distance of the predicted variables (Kaliyaperumal \& Kuppusamy, 2015; Rousseeuw \& Zomeren, 1990). Next, we tested our data for the normality distribution assumptions and found that these were consistent. The maximum values for the skewness and kurtosis were less than 2 and 5, respectively (Curran, West, \& Finch, 1996).

Next, a multicollinearity analysis was conducted using the variance inflation factor. All of the values were less than 2 , which is substantially lower than the recommended threshold of 10 (Hair, Black, Babin, \& Anderson, 2010). Therefore, multicollinearity was not a problem in our case.

We then performed an exploratory factor analysis (EFA) using the maximum likelihood method (Cudeck \& O’Dell, 1994; Fabrigar, Wegener, MacCallum, \& Strahan, 1999) and oblique rotation (promax) (Fabrigar et al., 1999) to verify that the research variable used in this study loaded on the same factors the authors proposed, these being organizational justice, SEIB, and leader humility. To extract the factors, items with eigenvalues greater than 1 and factor loadings greater than 0.50 were considered (Kaiser, 1974) as these thresholds achieve robust results and provide ease of interpretation. Similarly, factors with cross loadings, those not loading on their respective factors, and those not loading on any factor were dropped from the study (Ferguson, 1954). In our case, all items except for one had a factor loading lower than the decided threshold. Therefore, we decided to drop one item (item code: OJ4) from our study. Later, following Ferguson (1954), we re-ran the remaining items, seeking a more parsimonious factor structure, and found the three-dimensional factor solution with the highest loading on each factor (Hair et al., 2010). Kaiser-Mayer-Olkin (KMO) and Bartlett sphericity tests were taken into consideration to validate the loadings of the items on their respective measures. The results show that the KMO scores were high and within the range of acceptability. Similarly, the Bartlett test scores were also highly significant and within an acceptable range.

Last, we conducted a common method variance (CMV) analysis. Prior to considering the output of the extracted factors that were used to test for convergent and discriminant validity, we decided to verify whether CMV would be a problem for our data. We discerned that CMV may have existed since the data were collected on a self-reporting basis (Lindell \& Whitney, 2001). According to Podsakoff, MacKenzie, and Podsakoff (2012), statistical and procedural remedies can be employed to reduce potential bias. Our study already incorporated procedural remedies; for example, as we provided assurance for confidentiality and anonymity (Konrad \& Linnehan, 1995) and used validated scales, the results were less sensitive to potential bias (Doty \& Glick, 1998). However, as a statistical remedy, we used Harman's single factor test (Podsakoff, MacKenzie, Lee, $\&$ Podsakoff, 2003). We conducted an exploratory factor 
analysis (EFA) for all of the extracted items; this allowed us to load on a single factor with no rotation. The CMV results show that the aforementioned problem was not an issue in our study as the variance explained by a single factor $(27 \%)$ was less than the $50 \%$ threshold (Kutner, Nachtsheim, Neter, \& Li, 1996).

We also performed a CFA to validate our model. The extracted factor output was analyzed using three factors and 19 items. Gerbing and Anderson (1988) suggested applying CFA using at least three items in each construct to obtain an effective measurement and analysis. Our extracted factor output was consistent as each construct consisted of more than three items. Based on the model of the study (three factors and 19 items), the results show a goodness-of-fit index $(\mathrm{GFI})>0.90$, a comparative fit index $(\mathrm{CFI})>0.90$ and a root mean square error of approximation $($ RMSEA $)<0.10$. Hence, these conditions met the requirements of an acceptable model and indicated the unidimensionality of the factors (Hooper, Coughlan, \& Mullen, 2008). Table 2 presents the indices of the CFA model.

We also calculated the Cronbach's alpha, the composite reliability, the convergent validity, and the discriminant validity. The Cronbach's alpha and the composite reliability indicated that the construct reliability should be $\geq 0.70$ (Fornell \& Larcker, 1981; Götz, LiehrGobbers, \& Krafft, 2010). Similarly, for the convergent validity, the average variance extracted (AVE) should be $>0.50$ (Götz, et al., 2010; Hair, et al., 2010; Rutherford \& Hair, 1988). The discriminant validity was analyzed following the procedures recommended by Fornell and Larker (1981). Table 3 shows all of the values for the Cronbach's alpha, the composite reliability, and the factor loadings of each of the items and the construct.

Next, the descriptive statistics and correlation coefficients were derived. Table 4 shows the Pearson correlation coefficients, and the means, the standard deviations (SD), and the discriminant validity. All of the constructs were more strongly correlated to their own construct than with the other constructs.

\section{Results}

The PROCESS model (Hayes, 2012) was used to conduct the moderation analysis. The analyses of the main effect and the moderated relationships were tested independently in order to make the interpretations effective. Likewise, the interactions were analyzed using standard
Table 2

\section{Model fit indices}

\begin{tabular}{lccc}
\hline \multicolumn{1}{c}{ Fit indices } & GFI & CFI & RMSEA \\
\hline Measurement model & 0.95 & .934 & 0.43 \\
Threshold & $>0.90$ & $>.90$ & $<0.10$ \\
\hline
\end{tabular}

Table 3

Factor loadings and reliability of the items and constructs

\begin{tabular}{|c|c|c|c|c|c|}
\hline Factor name & $\begin{array}{l}\text { Items } \\
\text { coding }\end{array}$ & $\begin{array}{c}\text { Factor } \\
\text { loading }\end{array}$ & $\begin{array}{c}\text { Cronbach's } \\
\text { alpha }\end{array}$ & AVE & CR \\
\hline \multirow{5}{*}{$\begin{array}{l}\text { Service } \\
\text { Employees' } \\
\text { Innovative } \\
\text { Behavior (SEIB) }\end{array}$} & ESIB1 & 0.83 & \multirow{5}{*}{0.84} & \multirow[t]{5}{*}{0.71} & \multirow[t]{5}{*}{0.92} \\
\hline & ESIB2 & 0.81 & & & \\
\hline & ESIB3 & 0.80 & & & \\
\hline & ESIB4 & 0.86 & & & \\
\hline & ESIB5 & 0.85 & & & \\
\hline \multirow{6}{*}{$\begin{array}{l}\text { Organizational } \\
\text { Justice }(\mathrm{OJ})\end{array}$} & OJ1 & 0.85 & \multirow[t]{5}{*}{0.79} & \multirow[t]{5}{*}{0.71} & \multirow[t]{5}{*}{0.92} \\
\hline & $\mathrm{OJ} 2$ & 0.83 & & & \\
\hline & OJ3 & 0.88 & & & \\
\hline & OJ5 & 0.89 & & & \\
\hline & OJ6 & 0.72 & & & \\
\hline & OJ4* & - & - & - & - \\
\hline \multirow{9}{*}{$\begin{array}{l}\text { Leader Humility } \\
\text { (LH) }\end{array}$} & LH1 & 0.79 & \multirow[t]{9}{*}{0.89} & \multirow[t]{9}{*}{0.70} & \multirow[t]{9}{*}{0.95} \\
\hline & LH2 & 0.87 & & & \\
\hline & LH3 & 0.87 & & & \\
\hline & LH4 & 0.79 & & & \\
\hline & LH5 & 0.87 & & & \\
\hline & LH6 & 0.79 & & & \\
\hline & LH7 & 0.82 & & & \\
\hline & LH8 & 0.82 & & & \\
\hline & LH9 & 0.87 & & & \\
\hline
\end{tabular}

Note. ${ }^{\star}$ item deleted during EFA, therefore not considered for CFA.

Table 4

\section{Correlations and discriminant validity}

\begin{tabular}{lcclll}
\hline Constructs & Mean & SD & SEIB & OJ & LH \\
\hline SEIB & 3.43 & 0.94 & $\mathbf{0 . 8 4}$ & & \\
OJ & 3.62 & 0.82 & $0.22^{* *}$ & $\mathbf{0 . 8 4}^{*}$ & \\
LH & 2.76 & 0.82 & $0.18^{* *}$ & $0.14^{* *}$ & $\mathbf{0 . 8 3}^{*}$ \\
\hline
\end{tabular}

Note. ${ }^{\star}$ Discriminant validity, ${ }^{* *}$ Correlation coefficients significant at 0.01 level

deviations (Hayes, 2012) by plotting the conditional effect(s) with the standard deviations of $+/-1$. Moreover, to enhance the interpretability of the interaction effect within the range of data, all of the interactions were mean centered (Hayes, 2012). In addition, gender and marital status were considered as control variables during the moderation analysis, where gender was coded as $(0=$ "female"; $1=$ "male") and marital status was coded as 
( 0 = "single"; $1=$ "married"). Table 5 and models 1 and 2 summarize the main effects of organizational justice on SEIB, and the moderating effect of leader humility on the organizational justice-SEIB relationship, respectively.

Our first hypothesis proposes that organizational justice (OJ) would positively affect SEIB in the services sector. Table 5 (Model 1) indicates that $H 1(b=0.262$, $p<.001)$ is accepted. Also, the overall model with the predictor is statistically significant $[F(1,357)=19.712$, $p<.001$ ]. As shown on Table 5 (Model 2), the results for Hypothesis 2 also indicate that leader humility has a moderating effect on the relationship between organizational justice and SEIB in the services sector as the overall model is statistically significant $[F(5,353)=6.53, p<.001]$. Similarly, the interaction between organizational justice and leader humility accounts for more variance than either of these two factors alone $\left[\Delta R^{2}=.0082, F(1,353)=3.173, p<.05\right]$. Hence, $H 2(b=0.144, p<.05)$ is also accepted, and the two-way interaction is plotted in Figure $2(\mathrm{OJ} x \mathrm{LH})$.

\section{Table 5}

\section{Effect of Organizational Justice and Leader Humility on SEIB}

\begin{tabular}{lcl}
\hline \multicolumn{1}{c}{ Measures } & Model 1 & Model 2 \\
\hline Organizational justice $^{\mathrm{a}}(\mathrm{OJ})$ & $0.26^{* * *}$ & $0.26^{* * *}$ \\
Leader humility $^{\mathrm{b}}(\mathrm{LH})$ & - & $0.16^{* *}$ \\
Gender $^{\mathrm{d}}$ & - & 0.01 \\
Marital status $^{\mathrm{d}}$ & - & 0.05 \\
$\mathrm{R}$ & 0.22 & 0.28 \\
$\mathrm{R}^{2}$ & 0.05 & 0.08 \\
$\mathrm{~F}$ stat & $19.71^{* * *}$ & $6.53^{* * *}$ \\
Interaction: OJ x LH $^{*}$ & - & $0.14^{\mathrm{c} *}$ \\
$\Delta \mathrm{R}^{2}$ & - & 0.0082 \\
$\Delta \mathrm{F}$ & - & $3.17^{* * *}$ \\
\hline
\end{tabular}

Note. ${ }^{\text {a }}$ Predictor, ${ }^{\mathrm{b}}$ Moderator, ${ }^{\mathrm{c}}$ Mean centered interaction,

${ }^{\mathrm{d}}$ Control variables, ${ }^{* *} p<0.001,{ }^{* *} p<0.01,{ }^{*} p<0.05$

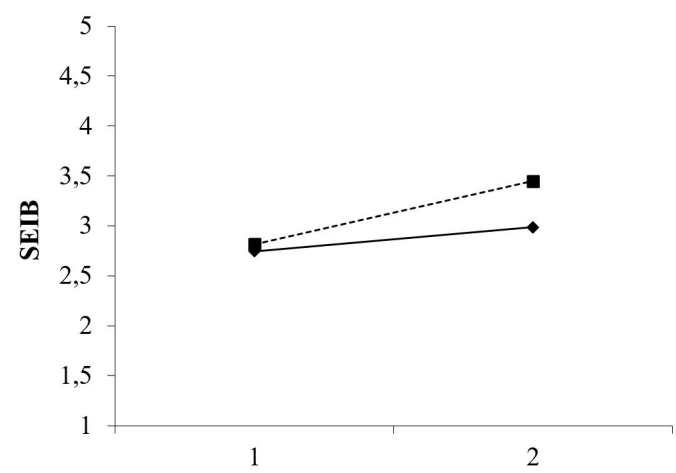

Figure 2. Conditional effect of OJ on ESIB at different levels of $\mathrm{LH}$

\section{Discussion}

This empirical study supports all of the stated hypotheses and the results contribute in the following four ways. First, the study analyzes innovative behaviors in services, a topic that has received little attention in the literature as most research is conducted on the manufacturing sector. This study bridges this gap by addressing the call for research (Li \& Hsu, 2016) on innovative behaviors in services and studies on SEIB at the individual level.

Second, as most research focuses on developed economies and individualistic societies, little is known about organizational justice in the context of a collectivist society in a developing country. As a result, this study considers organizational justice as a unidimensional construct and analyzes the effect of the overall perception of justice on SEIB in the context of Pakistan as a collectivist society and developing country. The results show that organizational justice has a positive effect on SEIB and the greater the perception of overall justice, the higher the SEIB. Hence, when the overall perception of justice is greater within the organization, employees working in Pakistan's services industries tend to exhibit higher levels of innovative behaviors. This result is consistent with a study conducted in the hospitality industry in Taiwan that uses a three-dimensional model (distributive, procedural, and interactional) of organizational justice and threedimensional innovative behaviors (idea generation, idea marketing, and idea practicing) (Hsu \& Wang, 2015). However, in regard to Pakistan's collectivist culture, this study provides some interesting insights. The results of the study are in line with perceptions of justice within workplace settings in individualistic cultures (Mueller \& Wynn, 2000). This result suggests that in the services sector in a collectivistic culture such as that found in Pakistan, in particular, overall perceptions of justice are highly valued. Additionally, in services sector organizations in Pakistan, when individuals perceive there is justice they exhibit innovative behaviors at the individual level. This is also in line with collectivist values, such as having a sense of belonging, a shared identity, and resource sharing; further, these values translate into the positive emotions that form emotional ties with the organization and later serve as motivational drivers of behaviors that improve employees' performance through their taking on extra roles (i.e., innovative behavior).

This study also makes broader contributions to the literature by validating the constructs of the behaviors 
(OJ, SEIB, and LH) utilized in other geographical regions. First, organizational justice has also been studied in other countries in relation to different sectors. For example, the results of organizational justice in this study are also consistent with a study on Islamic financial institutions in Malaysia, where the perception of overall justice was found to be significantly and positively related to organizational citizenship behaviors (Mohammad et al., 2016). Additionally, the scale of the overall perception of justice has also been utilized in the educational sector, the food service industry, and medical organizations in the US, and has been found to positively affect organizational citizenship behaviors (Ambrose \& Schminke, 2009; Mohammad et al., 2016). Moreover, Akram et al. (2016a) also studied different facets of organizational justice in relation to the telecommunications sector in China and found this to have a significant impact on the scale of three-dimensional innovative behaviors in this industry. Likewise, Akram et al. (2020) used knowledge sharing as a mediator to study a five-dimensional model of organizational justice in relation to the telecommunications sector in China and found that this has a significant impact on innovative behaviors in the industry. Second, studies on SEIB have been conducted on India's banking industry and Korea's airline industry. For example, Garg and Dhar (2017) found that leader exchange is positively related to SEIB in the public banking industry in India. Similarly, Lee and Hyun (2016) predicted SEIB-based self-esteem in the Korean airline industry. Third, the construct of leader humility has also been used in Portugal, Singapore, China, and the US. For instance, Rego et al. (2017) found humble leaders to be significantly more humble than transactional leaders in an experimental study using Portuguese and Singaporean samples. Similarly, in a sample of leaders in medical task forces in China, Wang et al. (2017) found leader humility to be positively related to employee creativity.

The results of this study are also consistent with studies conducted for different continents and regions. Many researchers have studied perceived organizational justice and leader humility in Asia, Australia, and Europe and found that perceptions of justice are analogous to the outcome variables. For example, Arici, Arasli, Çobanoğlu, and Hejraty Namin (2019) analyzed a three-dimensional model of organizational justice, using a sample from threeand four-star hotels in North Cyprus (intercontinental state). They found that the three-dimensional model of organizational justice is positively related to the outcome variable (i.e., job embeddedness) among frontline workers in family-run hotels. Similarly, Farid, Iqbal, Jawahar, Ma, and Khan (2019) used samples of healthcare workers in Pakistan (i.e., nurses) to study a three-dimensional justice model for a South Asian country. They concluded that all three dimensions have significant and positive relationships with organizational citizenship behaviors and work engagement in public hospitals. In the same vein, Abbas and Wu (2019a) analyzed overall fairness in Pakistan's services sector and found a positive relationship with innovative work behaviors. Likewise, a study conducted on the telecommunications sector in South Asia also concluded that organizational justice (two-dimensional model) is positively related to organizational trust and negatively related to turnover (Farooq \& Farooq, 2014). In the same vein, another study used a five-dimensional model to investigate the telecommunications sector in China and concluded that justice is positively associated with innovative behaviors (Akram et al., 2020). Further, Abbas and Wu (2019b) used a sample from Pakistan-a South Asian country — and found that leader humility is significantly and positively related to innovative behavior.

For East Asia, Lee, Kim, Son, and Kim (2015) used a four-dimensional organizational justice model on restaurants in South Korea and found that these dimensions are indirectly related and are mediated through affective and cognitive trust toward task performance that includes helping behaviors. Another study that used a two-dimensional organizational justice model compared China, South Korea, and Australia (Jiang, Gollan, \& Brooks, 2017). The authors found that, first, organizational justice is positively related to affective organizational commitment through organizational trust, in that university employees in Australia pay somewhat more attention to distributive justice than Chinese and South Korean university employees do. Second, when Australian university employees perceive procedural justice, they are more likely to reciprocate in organizational trust and affective organizational commitment than Chinese and South Koreans are when they have the same perceptions. Third, irrespective of the culture (East Asian and Australian), procedural justice carries more weight in winning organizational trust than distributive justice does. Additionally, a meta-analysis that used a twodimensional organizational justice model compared East Asians and North Americans (Li \& Cropanzano, 2009). Here, the authors used a tripartite model of self-concept to study the links between perceptions of justice and the 
four outcome variables of job satisfaction, organizational commitment, turnover intention, and trust. The study concluded that irrespective of the culture (East Asian and North American), employees pay attention to fair treatment in the workplace and may respond negatively when injustice is perceived within their organizations. In a comparative sense, Li and Cropanzano's (2009) study found that the effect of the perception of justice on the aforementioned outcome variables tends to be greater among North Americans than among East Asians. The difference is due to the fact pro-social behaviors, social harmony, and relational self-awareness are embedded in East Asians' collectivist culture. Moreover, Rego et al. (2017) used samples from China, Singapore, and Portugal to study humility in leaders and concluded that humble leaders significantly and positively contribute toward team performance. Keeping in mind the cultural differences between the three nations, the study by Rego et al. (2017) found no differences and concluded that the effect of humility among leaders on subordinates is identical across these three cultures. Therefore, humility among leaders may also be generalizable across cultures.

Considering Europe, Neveu and Kakavand (2019) studied a two-dimensional organizational justice model, using a public sector sample from France, and found an inverse relationship between perceptions of workplace justice and workplace corruption. Another study (Unterhitzenberger \& Bryde, 2018) linked a three-dimensional justice model, using samples from the United Kingdom and Central Europe, to workplace project performance and concluded that all of the dimensions of justice are positively associated with project performance but that procedural justice has greater impacts than distributive justice and distributive justice has greater impacts than interactional justice. Additionally, Sarti (2019) studied a two-dimensional justice model for Italy and concluded that procedural and distributive justice are positively related to workplace engagement. Furthermore, Strobl, Niedermair, Matzler, and Mussner (2019) studied the relationship between leaders' personality traits and innovative behaviors and found that leader humility is positively associated with innovative behaviors among executives in Austria.

Third, this study contributes to the literature as it analyzes the interaction effect of leader humility. Since most of the literature on leader humility is theoretical and lacks empirical support, this empirical study analyzes the moderating effect of leader humility on the relationship between organizational justice and SEIB. The results show that leader humility moderates the positive relationship between organizational justice and SEIB, such that high humility results in higher SEIB. Hence, leader humility plays a significant role in the services sector in Pakistan. Organizations that are able to maintain a perception of fairness may also benefit from leader humility in that leaders with greater humility serve as catalysts to SEIB. Indeed, when employees perceive fairness within their organization, leaders with high humility accelerate SEIB. The finding that humility is a catalyst to innovative behaviors is consistent with the collectivist pattern. For instance, in a collectivist culture, criticism is discouraged and cooperation is highly regarded (Goncalo \& Staw, 2006; Tjosvold, Law, \& Sun, 2003). Similarly, the concept of humility neither follows disrespectful behaviors nor has the intension to harm others (Richard, 1992) but strongly promotes teachability and extends cooperation to followers (Owens \& Heckman, 2012). These supportive behaviors toward employees increase work participation (Janssen, 2005) and encourage employees to exhibit discretionary behaviors (innovative behaviors).

Fourth, this study emphasizes and confirms the role of social exchange theory, signaling theory, and regulatory fit theory by outlining the role of leader humility and the perception of overall justice in employees' innovative behaviors. Theorists and practitioners have used social exchange theory as a theoretical lens through which to interpret social interactions among employees, organizations, supervisors, co-workers, and peers (Rupp, 2011). Also, different scholars have explained organizational support (Rhoades \& Eisenberger, 2002), job satisfaction (Lavelle, Rupp, \& Brockner, 2007), and organizational commitment (Klein, Molloy, \& Cooper, 2009) through social exchange. Despite utilizing social exchange theory to interpret relationships and explain constructs, studies have rarely utilized this theory to explain how ties between an organization and its employees can have an impact on innovative behaviors in the services sector. This research highlights a basic assumption - the benefit of reciprocation in social exchange theory; it also explains the relationship between the overall perception of justice and innovative behaviors in services. The findings of the study suggest that employees positively reciprocate the justice they perceive. This result contributes to the literature in three ways. First, this study provides further evidence that connects the organizational factor of overall justice with employees' observable innovative behaviors in services. Second, the study directs attention toward 
firms operating in the services sector, from the point of view of both economic and social exchange. The study shows how service organizations can benefit from social exchange and encourage employees to assume behaviors where they take on extra roles. Last, the study explicates social connections or employees' feelings of mutual trust, affiliation, and belongingness in the organizations they work for, which results in their adopting discretionary behaviors (i.e., innovative behaviors).

The literature has adopted signaling theory to explain firms' financial abilities to investors (Zhang \& Wiersema, 2009), their social values and demographic diversity to stakeholders (Miller \& Triana, 2009), and their recruitment practices to prospective employees (Suazo, Martínez, \& Sandoval, 2009). However, little attention has been given to leaders' behaviors as signals, such as the concept of humility in leadership. The findings of this study show that humility serves as a positive signal that receives positive feedback (innovative behaviors) in the services sector. This result contributes to the literature in the following ways. First, as financial statements (Zhang \& Wiersema, 2009), diversity (Miller \& Triana, 2009), and policies (Suazo et al., 2009) are considered signals, similarly, employees also consider leaders' behaviors as signals. Second, humility is a positive signal that stimulates employees to go the extra mile and perform extra-role behaviors (i.e., innovative behaviors). Last, humble leaders signal that there is an atmosphere of psychological freedom and workplace autonomy through behaviors that enable employees to implement novel ideas. Along the same lines, the results of this study are also consistent with regulatory fit theory. The findings conclude that employees positively reciprocate perceptions of fairness (social exchange theory) and perceptions of leader humility (signal theory) encourage employees to become involved in innovative behaviors. These interactions clearly indicate that when employees perceive higher leader humility, their involvement in innovative behaviors will increase, thus indicating that when one condition is present, then the other is amplified.

These results are found to be consistent with the literature For instance, Cesario et al. (2004) noted that indistinguishable messages from different sources (i.e., the organization and the leader) serve as strong signals that will have greater impacts on recipients than individual sources do (the organization or the leader); further, indistinguishable messages from different sources are reciprocated with actions that lead to greater benefits, such as employees becoming involved in developing creative solutions and implementing novel ideas. Similarly, in their study, Kruglanski et al. (2007) also found that different leadership styles strengthen the potential responses of employees (i.e., job satisfaction). This result extends the existing knowledge in the literature by defining innovative employees as the focus of promotion, which will lead to a high level of gains in advancements and accomplishments. When these employees feel right about their work situation, they will react positively to the messages (overall justice and humility) that are sent through different means (organizations and leaders). Putting this of all together, our findings suggest that when an organization maintains an environment of fairness and encourages humility in its leaders, this could stimulate innovative behaviors among employees and assist organizations in collectivist developing countries such as those in South Asia to reach their goals.

\section{I Practical implications}

This study has practical implications for both academicians and practitioners in terms of some workplace conditions that can contribute to employees' innovative behavior in service industries. The study also extends the predictive validity of the overall justice scale. The results emphasize the predictive role of the overall perception of justice in the context of service industries in Pakistan, a collectivist society and a developing country. Furthermore, researchers in South Asian countries can either adopt or adapt the scales of the overall perception of justice, leader humility, and service employees' innovative behaviors because this study confirms the validity and reliability of the scales. The results also suggest important managerial implications. First, they emphasize the importance of fairness within organizations, such as in treating employees justly in work settings and maintaining an atmosphere of fairness within the organization. This positive perception of fairness will encourage employees to reciprocate by demonstrating discretionary innovative behaviors (SEIB); it will also help employees attain personal, departmental, and organizational goals. Second, employees should encourage humility in their leaders. Humble leaders serve as catalysts to SEIB. As shown in the results, a high level of humility boosts innovative behaviors among employees in that it encourages them to go the extra mile and demonstrate innovative behaviors in attaining organizational objectives. Moreover, managers are also strongly recommended to demonstrate some specific behavioral tendencies, such as: (1) a willingness to admit mistakes and encourage new 
ideas; (2) paying attention to others by putting themselves in their place; (3) appreciating employees' strengths and contributions; and (4) providing feedback and practicing openness. These tendencies, in aggregate, make leaders supportive and humble and reduce incidences of contextual uncertainties within the workplace. Ultimately, these behaviors will engage employees to undertake trial-anderror experimentation and foster innovative behaviors within their organization.

This study also presents important insights for organizations that are planning to invest in the services sector in Pakistan. Since the China-Pakistan economic corridor (CPEC) is making it attractive for overseas organizations to invest in Pakistan, this study plays a significant role in providing an understanding of innovative behaviors in services in a developing economy and a collectivist culture. It recommends that overseas companies consider instilling an environment of fairness within their organizations and that they pay attention to humility in leaders' behaviors when operating within industries situated within a collectivist society. This may result in an increase in the level of innovative behavior among employees and this is something businesses need to achieve in the contemporary world.

\subsection{Limitations and future research}

This study is not free from limitations. First, it is cross-sectional in nature; therefore, the direction of causality is a matter that calls for attention. Second, the study sample is obtained from services sector organizations, which limits the generalizability of the results to other sectors. Third, the study only addresses the promotional focus of the regulatory orientation in regulatory fit theory. Last, the study hypothesizes regarding the impact of humility and perceptions of justice on employees of service organizations within Pakistan, the setting of a collectivist society within a developing country; thus, the findings cannot be extrapolated to other settings. Further, a careful analysis is recommended when generalizing the results to other collectivist cultures and developing economies. Future studies could replicate similar approaches for researching other sectors (i.e., manufacturing) when undertaking longitudinal studies in other Asian countries. Additionally, when conceptualizing a similar model, it is recommended that a comparative analysis between the services and manufacturing sectors analyzes the effects of leader humility in relation to both organizational justice and innovative behaviors.

\section{Conclusion}

This study empirically analyzes the effects of organizational justice on employees' innovative work behaviors in the services sector in Pakistan, a collectivist society and a developing country. It also analyzes the moderating role of leader humility in relation to the aforementioned constructs, which is a less empirically studied concept. Studies on the said constructs are sparse and limited attention is given to the Asian context. Therefore, this research contributes to the literature by analyzing the impact of the overall perception of justice within an organization and leader humility on service employees' innovative behaviors through the lens of social exchange theory and signaling theory. The study concludes that when employees perceive fairness within an organization, they reciprocate with discretionary behaviors. The findings also show that humility, as a positive signal, increases innovative behaviors. Further, in light of these findings, this study encourages managers to instill humility in relation to the way they conduct themselves within the organizations they work for.

\section{References}

Abbas, W., \& Wu, W. (2019a). Employee innovativeness, fairness and organizational support: An empirical assessment. Human Systems Management, 38(2), 169-177. doi: $10.3233 / \mathrm{hsm}-180385$

Abbas, W., \& Wu, W. (2019b). The moderating role of intrapreneurial personality in relation between leader humility and innovative behavior. Human Systems Management, 38(4), 329-337. doi: 10.3233/hsm-190548

Afsar, B., Badir, Y. F., \& Saeed, B. B. (2014). Transformational leadership and innovative work behavior. Industrial Management \& Data Systems, 114(8), 1270-1300. doi: 10.1108/IMDS-05-2014-0152

Aguiar-Quintana, T., Araujo-Cabrera, Y., \& Park, S. (2020). The sequential relationships of hotel employees' perceived justice, commitment, and organizational citizenship behaviour in a high unemployment context. Tourism Management Perspectives, 35. doi: 10.1016/j. tmp.2020.100676

Akram, T., Haider, M. J., \& Feng, Y. X. (2016a). The effects of organizational justice on the innovative work 
behavior of employees: an empirical study from China. Journal of Creativity and Business Innovation, 2, 114-126.

Akram, T., Lei, S., \& Haider, M. J. (2016b). The impact of relational leadership on employee innovative work behavior in the IT industry of China. Arab Economic and Business Journal, 11(2), 153-161. doi: 10.1016/j.aebj.2016.06.001

Akram, T., Lei, S., Haider, M. J., \& Hussain, S. T. (2020). The impact of organizational justice on employee innovative work behavior: Mediating role of knowledge sharing. Journal of Innovation \& Knowledge, 5(2), 117-129. doi: 10.1016/j.jik.2019.10.001

Allen, J. A., Diefendorff, J. M., \& Ma, Y. (2014). Differences in emotional labor across cultures: A comparison of Chinese and US service workers. Journal of Business and Psychology, 29(1), 21-35.

Amabile, T. M., \& Pratt, M. G. (2016). The dynamic componential model of creativity and innovation in organizations: Making progress, making meaning. Research in Organizational Behavior, 36, 157-183. doi: org/10.1016/j.riob.2016.10.001

Ambrose, M. L., \& Arnaud, A. (2005). Distributive and procedural justice: Construct distinctiveness, construct interdependence, and overall justice. In J. Greenberg \& J. A. Colquitt (Eds.), The handbook of organizational justice (pp. 59-84). Mahwah, NJ: Erlbaum

Ambrose, M. L., \& Schminke, M. (2009). The role of overall justice judgments in organizational justice research: a test of mediation. Journal of Applied Psychology, 94(2), 491-500. doi: 10.1037/a0013203

Arici, H. E., Arasli, H., Çobanoğlu, C., \& Hejraty Namin, B. (2019). The Effect Of Favoritism On Job Embeddedness In The Hospitality Industry: A Mediation Study Of Organizational Justice. International Journal of Hospitality \& Tourism Administration, 1-29. doi: 10.1080/15256480.2019.1650685

Axtell, C. M., Holman, D. J., Unsworth, K. L., Wall, T. D., Waterson, P. E., \& Harrington, E. (2000). Shopfloor innovation: Facilitating the suggestion and implementation of ideas. Journal of Occupational and Organizational Psychology, 73(3), 265-285. doi: 10.1348/096317900167029
Bashir, S., Khattak, H. R., Hanif, A., \& Chohan, S. N. (2011). Whistle-blowing in public sector organizations: Evidence from Pakistan. The American Review of Public Administration, 41(3), 285-296. doi: 10.1177/0275074010376818

Binnewies, C., Ohly, S., \& Sonnentag, S. (2007). Taking personal initiative and communicating about ideas: What is important for the creative process and for idea creativity? European Journal of Work and Organizational Psychology, 16(4), 432-455. doi:10.1080/13594320701514728

Blau, P. M. (1964). Exchange and power in social life. New York: John Wiley \& Sons, Inc.

Campo, S., Díaz, A. M., \& Yagüe, M. J. (2014). Hotel innovation and performance in times of crisis. International Journal of Contemporary Hospitality Management, 26(8), 1292-1311. doi: 10.1108/IJCHM-08-2013-0373

Castro, M. P., \& Guimaraes, T. A. (2020). Dimensions that influence the innovation process in justice organizations. Innovation \& Management Review, 17(2), 215-231. doi: 10.1108/inmr-10-2018-0075

Cesario, J., Grant, H., \& Higgins, E. T. (2004). Regulatory Fit and persuasion: Transfer from "Feeling Right.". Journal of Personality and Social Psychology, 86(3), 388-404. doi:10.1037/0022-3514.86.3.388

Cesario, J., Higgins, E. T., \& Scholer, A. A. (2008). Regulatory fit and persuasion: Basic principles and remaining questions. Social and Personality Psychology Compass, 2(1), 444-463. doi:10.1111/j.1751-9004.2007.00055.x

Chao, C.-Y., Lin, Y.-S., Cheng, Y.-L., \& Tseng, Y.-C. (2011). Employee innovation, supervisory leadership, organizational justice, and organizational culture in Taiwan's manufacturing industry. African Journal of Business Management, 5(6), 2501-2511.

Chao, G. T., \& Moon, H. (2005). The cultural mosaic: A metatheory for understanding the complexity of culture. Journal of Applied Psychology, 90(6), 1128-1140. doi: 10.1037/0021-9010.90.6.1128

Cohen, A., \& Ehrlich, S. (2019). Exchange variables, organizational culture and their relationship with constructive deviance. Management Research Review, 42(12), 1423-1446. doi: 10.1108/mrr-09-2018-0354 
Cohen, J. (1977). F Tests of variance proportions in multiple regression/correlation analysis. In J. Cohen. Statistical Power Analysis for the Behavioral Sciences (Cap. 9, pp. 407-453).New York: Academic Press.

Colquitt, J. A., Conlon, D. E., Wesson, M. J., Porter, C. O. L. H., \& Ng, K. Y. (2001). Justice at the millennium: A meta-analytic review of 25 years of organizational justice research. Journal of Applied Psychology, 86(3), 425-445. doi: 10.1037/0021-9010.86.3.425

Comte-Sponville, A. (2002). A small treatise on the great virtues: The uses of philosophy in everyday life. New York: Henry Holt \& Company.

Connelly, B. L., Certo, S. T., Ireland, R. D., \& Reutzel, C. R. (2010). Signaling theory: a review and assessment. Journal of Management, 37(1), 39-67. doi: $10.1177 / 0149206310388419$

Conner, D. S. (2003). Socially appraising justice: A crosscultural perspective. Social Justice Research, 16(1), 29-39. doi: 10.1023/A:1022922010184

Cooper-Thomas, H. D., Xu, J., \& Saks, M. A. (2018). The differential value of resources in predicting employee engagement. Journal of Managerial Psychology, 33(4-5), 326-344. doi: 10.1108/JMP-12-2017-0449

Cropanzano, R., \& Ambrose, M. L. (2001). Procedural and distributive justice are more similar than you think: A monistic perspective and a research agenda. In J. Greenberg $\&$ R. Cropanzano (Eds.), Advances in organizational justice (Cap. 4, pp. 119-150). California: Stanford University Press.

Cropanzano, R., \& Rupp, D. E. (2008). Social exchange theory and organizational justice: Job performance, citizenship behaviors, multiple foci, and a historical integration of two literatures. In S. W. Gilliland, D. D. Steiner \& D. P. Skarlicki (Eds.), Justice, morality, and social responsibility (Cap.3, pp.63-100). Charlotte, Nc: Information Age Publishing.

Cudeck, R., \& O’Dell, L. L. (1994). Applications of standard error estimates in unrestricted factor analysis: Significance tests for factor loadings and correlations. Psychological Bulletin, 115(3), 475-487. doi: 10.1037/0033-2909.115.3.475

Curran, P. J., West, S. G., \& Finch, J. F. (1996). The robustness of test statistics to nonnormality and specification error in confirmatory factor analysis. Psychological methods, 1(1), 16-29. doi: 10.1037/1082-989X.1.1.16

De Jong, J., \& Den Hartog, D. (2010). Measuring innovative work behaviour. Creativity and Innovation Management, 19(1), 23-36. doi:10.1111/j.1467-8691.2010.00547.x

Demir, M., Guney, S., Akyurek, S., Ugural, M., \& Aslan, I. (2017). Effect of managers' organizational justice understanding on the level of employees' organizational commitment and job satisfaction. Revista de Cercetare si Interventie Sociala, 58, 146-165.

Doty, D. H., \& Glick, W. H. (1998). Common methods bias: does common methods variance really bias results? Organizational research methods, 1(4), 374-406. doi: 10.1177/109442819814002

Emmons, R. A. (2000). Is spirituality an intelligence? Motivation, cognition, and the psychology of ultimate concern. The International Journal for the psychology of religion, 10(1), 3-26. doi: 10.1207/s15327582ijpr1001_2

Enz, C. A., \& Siguaw, J. A. (2003). Revisiting the best of the best: Innovations in hotel practice. Cornell Hotel and Restaurant Administration Quarterly, 44(5-6), 115-123. doi:10.1177/001088040304400516

Fabrigar, L. R., Wegener, D. T., MacCallum, R. C., \& Strahan, E. J. (1999). Evaluating the use of exploratory factor analysis in psychological research. Psychological Methods, 4(3), 272-299. doi: 10.1037/1082-989X.4.3.272

Farid, T., Iqbal, S., Jawahar, I. M., Ma, J., \& Khan, M. K. (2019). The interactive effects of justice perceptions and Islamic work ethic in predicting citizenship behaviors and work engagement. Asian Business \& Management, 18(1), 31-50. doi: 10.1057/s41291-018-00049-9

Farooq, M., \& Farooq, O. (2014). Organizational justice, employee turnover, and trust in the workplace: A study in South Asian telecommunication companies. Global Business and Organizational Excellence, 33(3), 56-62. doi: 10.1002/joe.21539

Faul, F., Erdfelder, E., Buchner, A., \& Lang, A.-G. (2009). Statistical power analyses using $G^{*}$ Power 3.1: Tests for correlation and regression analyses. Behavior Research Methods, 41(4), 1149-1160. doi: 10.3758/BRM.41.4.1149 
Ferguson, G. A. (1954). The concept of parsimony in factor analysis. Psychometrika, 19(4), 281-290. doi: 10.1007/BF02289228

Folger, R., \& Cropanzano, R. (1998). Organizational justice and human resource management. Thousand Oaks: Sage.

Fornell, C., \& Larcker, D. F. (1981). Evaluating structural equation models with unobservable variables and measurement error. Journal of marketing research, 18(1), 39-50. doi: $10.2307 / 3151312$

Garg, S., \& Dhar, R. (2017). Employee service innovative behavior: the roles of leader-member exchange (LMX), work engagement, and job autonomy. International Journal of Manpower, 38(2), 242-258. doi: 10.1108/IJM-04-2015-0060

Gerbing, D. W., \& Anderson, J. C. (1988). An updated paradigm for scale development incorporating unidimensionality and its assessment. Journal of Marketing Research, 25(2), 186-192. doi: 10.2307/3172650

Ghosh, K. (2015). Developing organizational creativity and innovation: Toward a model of self-leadership,employee creativity,creativity climate and workplace innovative orientation. Management Research Review, 38(11), 11261148. doi:10.1108/MRR-01-2014-0017

Goncalo, J. A., \& Staw, B. M. (2006). Individualismcollectivism and group creativity. Organizational Behavior and Human Decision Processes, 100(1), 96-109. doi: 10.1016/j.obhdp.2005.11.003

Gonçalves, L., \& Brandão, F. (2017). The relation between leader's humility and team creativity: The mediating effect of psychological safety and psychological capital. International Journal of Organizational Analysis, 25(4), 687-702. doi: 10.1108/IJOA-06-2016-1036

Götz, O., Liehr-Gobbers, K., \& Krafft, M. (2010). Evaluation of structural equation models using the partial least squares (PLS) Approach. In V. E. Vinzi, W. W. Chin, J. Henseler \& H. Wang (Eds.), Handbook of Partial Least Squares: Concepts, Methods and Applications (Cap. 29, pp. 691-711). Berlin, Heidelberg: Springer Berlin Heidelberg.

Grace, D., King, C., \& Lo Iacono, J. (2017). Workplace relationship cohesion: An internal customers' perspective. Journal of Service Theory and Practice, 27(1), 129-150. doi: 10.1108/JSTP-07-2015-0175
Greenberg, J. (1987). A taxonomy of organizational justice theories. Academy of Management Review, 12(1), 9-22. doi: 10.5465/amr.1987.4306437

Greenberg, J. (1990). Organizational Justice: Yesterday, Today, and Tomorrow. Journal of Management, 16(2), 399-432. doi: 10.1177/014920639001600208

Greenberg, J., \& Colquitt, J. A. (2013). Handbook of organizational justice. New York: Psychology Press.

Hair, J. F., Jr., Black, W. C., Babin, B. J., \& Anderson, R. E. (2010). Multivariate data analysis (7th ed.). Upper Saddle River, NJ: Prentice hall.

Hayes, A. F. (2012). PROCESS: a versatile computational tool for observed variable mediation, moderation, and conditional process modeling [White Paper]. Retrieved from http://www.afhayes.com/public/process2012.pdf

Higgins, E. T. (2005). Value from regulatory fit. Current Directions in Psychological Science, 14(4), 209-213. doi:10.1111/j.0963-7214.2005.00366.x

Hoorn, A. van (2015). Individualist-collectivist culture and trust radius: A multilevel approach. Journal of Cross-Cultural Psychology, 46(2), 269-276. doi: 10.1177/0022022114551053

Hofstede, G. (1991). Organizations and cultures and: Software of the mind. New York: McGrawHill.

Hofstede, G. (2001). Culture's consequences: Comparing values, behaviors, institutions and organizations across nations. Thousand Oaks, CA: Sage.

Hofstede, G. (2018, january 20). Hofstede Insights. Retrieved from https://www.hofstede-insights.com

Hofstede, G., Bond, M. H., \& Luk, C.-L. (1993). Individual perceptions of organizational cultures: a methodological treatise on levels of analysis. Organization Studies, 14(4), 483-503. doi: 10.1177/017084069301400402

Hooper, D., Coughlan, J., \& Mullen, M. (2008). Structural equation modelling: guidelines for determining model fit. Electronic Journal of Business Research Method, 6(1), 53-60.

Hsu, J.- L., \& Wang, J.-H. (2015). Exploring the effects of organizational justice on employees' innovative behavior in hospitality industry from the aspect of organizational 
support. Revista de Cercetare si Interventie Sociala, 49, 113-126.

Hu, M.-L. M., Horng, J.-S., \& Sun, Y.-H. C. (2009). Hospitality teams: Knowledge sharing and service innovation performance. Tourism Management, 30(1), 41-50. doi: 10.1016/j.tourman.2008.04.009

Jakopec, A., \& Sušanj, Z. (2014). Effects of (Mis) alignment between supervisory and organizational justice. Društvena istraživanja: časopis za opća društvena pitanja, 23(4), 615-637. doi: 10.5559/di.23.4.04

Janssen, O. (2000). Job demands, perceptions of effortreward fairness and innovative work behaviour. Journal of Occupational and Organizational Psychology, 73(3), 287-302. doi: 10.1348/096317900167038

Janssen, O. (2005). The joint impact of perceived influence and supervisor supportiveness on employee innovative behaviour. Journal of Occupational and Organizational Psychology, 78(4), 573-579. doi: 10.1348/096317905X25823

Javidan, M., Dorfman, P. W., Luque, M. S., de, \& House, R. J. (2006). In the eye of the beholder: Cross cultural lessons in leadership from project GLOBE. Academy of management perspectives, 20(1), 67-90.

Jiang, Z., Gollan, P. J., \& Brooks, G. (2017). Relationships between organizational justice, organizational trust and organizational commitment: a cross-cultural study of China, South Korea and Australia. The International Journal of Human Resource Management, 28(7), 973-1004. doi: 10.1080/09585192.2015.1128457

Judge, W. Q., Fryxell, G. E., \& Dooley, R. S. (1997). The new task of r\&d management: Creating goal-directed communities for innovation. California Management Review, 39(3), 72-85. doi: 10.2307/41165899

Kaiser, H. F. (1974). An index of factorial simplicity. Psychometrika, 39(1), 31-36. doi: 10.1007/bf02291575

Kaliyaperumal, S. K., \& Kuppusamy, M. (2015). Outlier detection in multivariate data. Journal Of Applied Mathematical Siences, 9, 2317-2324.

Kashif, M., \& Khattak, A. (2017). Ethical intentions among frontline employees working in the US-based fast food chains in Pakistan: The moderating role of love of money. British Food Journal, 119(7), 1547-1561. doi: 10.1108/BFJ-09-2016-0396

Kerwin, S., Jordan, J. S., \& Turner, B. A. (2015). Organizational justice and conflict: do perceptions of fairness influence disagreement? Sport Management Review, 18(3), 384-395. doi: 10.1016/j.smr.2014.10.005

Kesting, P., \& Ulhøi, J. P. (2010). Employee-driven innovation: extending the license to foster innovation. Management Decision, 48(1), 65-84. doi: 10.1108/00251741011014463

Khaola, P., \& Coldwell, D. (2019). Explaining how leadership and justice influence employee innovative behaviours. European Journal of Innovation Management, 22(1), 193-212. doi: 10.1108/ejim-08-2017-0103

Kim, H., \& Qu, H. (2020). The mediating roles of gratitude and obligation to link employees' social exchange relationships and prosocial behavior. International Journal of Contemporary Hospitality Management, ahead-of-print. doi: 10.1108/IJCHM-04-2019-0373

Kim, S., Chung, J.-E., \& Suh, Y. (2016). Multiple reference effects on restaurant evaluations: A cross-cultural study. International Journal of Contemporary Hospitality Management, 28(7), 1441-1466. doi: 10.1108/IJCHM-05-2014-0220

Kim, T. T., \& Lee, G. (2013). Hospitality employee knowledge-sharing behaviors in the relationship between goal orientations and service innovative behavior. International Journal of Hospitality Management, 34, 324-337. doi: 10.1016/j.ijhm.2013.04.009

Klein, H. J., Molloy, J. C., \& Cooper, J. T. (2009). Conceptual foundations: Construct definitions and theoretical representations of workplace commitments. In H. J. Klein, T. E. Becker, \& J. P. Meyer (Eds.), Commitment in organizations: Accumulated wisdom and New Directions (Cap.1, pp. 3-26). New York, NY: Routledge.

Konrad, A. M., \& Linnehan, F. (1995). Formalized HRM structures: coordinating equal employment opportunity or concealing organizational practices? Academy of Management Journal, 38(3), 787-820. doi: 10.5465/256746

Kruglanski, A. W., Pierro, A., \& Higgins, E. T. (2007). Regulatory mode and preferred leadership styles: How fit increases job satisfaction. Basic and Applied Social Psychology, 29(2), 137-149. doi:10.1080/01973530701331700 
Kutner, M. H., Nachtsheim, C. J., Neter, J., \& Li, W. (1996). Applied linear statistical models (5th ed.). Chicago: McGraw-Hill.

Larson, M. (2011). Innovation and creativity in festival organizations. Journal of Hospitality Marketing \& Management, 20(3-4), 287-310. doi:10.1080/193686 23.2011.562414

Lavelle, J. J., Rupp, D. E., \& Brockner, J. (2007). Taking a multifoci approach to the study of justice, social exchange, and citizenship behavior: The target similarity model. Journal of Management, 33(6), 841-866. doi:10.1177/0149206307307635

Lee, K., Gizzarone, M., \& Ashton, M. C. (2003). Personality and the likelihood to sexually harass. Sex Roles, 49(1-2), 59-69. doi: 10.1023/A:1023961603479

Lee, K.-H., \& Hyun, S. S. (2016). An extended model of employees' service innovation behavior in the airline industry. International Journal of Contemporary Hospitality Management, 28(8), 1622-1648. doi: 10.1108/ IJCHM-03-2015-0109

Lee, Y.-K., Kim, S., Son, M.-H., \& Kim, M.-S. (2015). Linking Organizational Justice to Job Performance: Evidence from the Restaurant Industry in East Asia. Asia Pacific Journal of Tourism Research, 20(sup1), 1527-1544. doi: 10.1080/10941665.2015.1016052

Li, A., \& Cropanzano, R. (2009). Do east asians respond more/less strongly to organizational justice than North Americans? A meta-analysis. Journal of Management Studies, 46(5), 787-805. doi: 10.1111/j.1467-6486.2009.00825.x

Li, M., \& Hsu, C. H. C. (2016). A review of employee innovative behavior in services. International Journal of Contemporary Hospitality Management, 28(12), 28202841. doi: 10.1108/IJCHM-04-2015-0214

Lindell, M. K., \& Whitney, D. J. (2001). Accounting for common method variance in cross-sectional research designs. Journal of Applied Psychology, 86(1), 114-121. doi: 10.1037/0021-9010.86.1.114

Lukes, M., \& Stephan, U. (2017). Measuring employee innovation: A review of existing scales and the development of the innovative behavior and innovation support inventories across cultures. International Journal of
Entrepreneurial Behavior \& Research, 23(1), 136-158. doi:10.1108/IJEBR-11-2015-0262

Luu, T. T. (2020). Can sales leaders with humility create adaptive retail salespersons? Psychology \& Marketing, 37(9), 1292-1315. doi: 10.1002/mar.21365

Mao, J., Chiu, C.-Y., Owens, B. P., Brown, J. A., \& Liao, J. (2019). Growing followers: exploring the effects of leader humility on follower self-expansion, self-efficacy, and performance. Journal of Management Studies, 56(2), 343-371. doi: 10.1111/joms.12395

Mariappanadar, S. (2018). The impact of dissonance in schema based leadership perceptions on employee engagement: Evidence from Australia. Personnel Review, 47(7), 1309-1329. doi: 10.1108/pr-03-2017-0081

Miller, T., \& Triana, M. D. C. (2009). Demographic diversity in the boardroom: Mediators of the board diversity-firm performance relationship. Journal of Management Studies, 46(5), 755-786. doi:10.1111/j.1467-6486.2009.00839.x

Ministry of Finance. (2018a). Pakistan economic survey 2017-18, growth and investment (pp. 1-12): Ministry of Finance, Government of Pakistan. Retrieved from http:// www.finance.gov.pk/survey_1718.html

Ministry of Finance. (2018b). Three member delegation of ACCA Pakistan called on the MOS for Finance Rana Muhammad Afzal Khan (PR No. 2275). Retrieved Feb 16, 2018, from Ministry of Finance http://www.finance. gov.pk/press_releases.html

Minkov, M., Dutt, P., Schachner, M., Morales, O., Sanchez, C., Jandosova, J., Khassenbekov, Y. \& Mudd, B. (2017). A revision of Hofstede's individualism-collectivism dimension: A new national index from a 56-country study. Cross Cultural \& Strategic Management, 24(3), 386-404. doi: 10.1108/CCSM-11-2016-0197

Mohammad, J., Quoquab, F., Makhbul, Z. M., \& Ramayah, T. (2016). Bridging the gap between justice and citizenship behavior in Asian culture. Cross Cultural \& Strategic Management, 23(4), 633-656. doi: 10.1108/ CCSM-08-2015-0097

Momeni, M., Ebrahimpour, H., \& Ajirloo, M. B. (2014). Surveying the impact of inferential organizational justice on innovative work behavior. Singaporean Journal of Business, Economics and Management Studies, 2(9), 1-8. 
Morris, J. A., Brotheridge, C. M., \& Urbanski, J. C. (2005). Bringing humility to leadership: antecedents and consequences of leader humility. Human Relations, 58(10), 1323-1350. doi: 10.1177/0018726705059929

Mueller, C. W., \& Wynn, T. (2000). The degree to which justice is valued in the workplace. Social Justice Research, 13(1), 1-24. doi: 10.1023/a:1007515618127

Mumford, M. D. (2003). Where have we been, where are we going? Taking stock in creativity research. Creativity Research Journal, 15(2-3), 107-120. doi: 10.1080/10400419.2003.9651403

Murphy-Berman, V., \& Berman, J. J. (2002). CrossCultural Differences in Perceptions of Distributive Justice: A Comparison of Hong Kong and Indonesia. Journal of Cross-Cultural Psychology, 33(2), 157-170. doi: 10.1177/0022022102033002003

Neveu, J.-P., \& Kakavand, B. (2019). Endangered Resources: The role of organizational justice and interpersonal trust as signals for workplace corruption. Relations industrielles / Industrial Relations, 74(3), 498-524. doi: 10.7202/1065170ar

Nielsen, R., \& Marrone, J. A. (2018). Humility: Our current understanding of the construct and its role in organizations. International Journal of Management Reviews, 20(4), 805-824. doi: 10.1111/ijmr.12160

Noon, J. M., \& Lewis, J. R. (1992). Therapeutic strategies and outcomes: Perspectives from different cultures. British journal of medical psychology, 65(2), 107-117.

Noor, H. M., \& Dzulkifli, B’a. (2013). Assessing leadership practices, organizational climate and its effect towards innovative work behaviour in $\mathrm{R} \& \mathrm{D}$. International Journal of Social Science and Humanity, 3(2), 129-133. doi: 10.7763/IJSSH.2013.V3.211

Nusair, N., Ababneh, R., \& Bae, Y. K. (2012). The impact of transformational leadership style on innovation as perceived by public employees in Jordan. International Journal of Commerce and Management, 22(3), 182-201. doi: 10.1108/10569211211260283

Oldham, G. R., \& Cummings, A. (1996). Employee creativity: Personal and contextual factors at work. Academy of Management Journal, 39(3), 607-634. doi:10.5465/256657
Ottenbacher, M. C. (2007). Innovation management in the hospitality industry: Different strategies for achieving success. Journal of Hospitality \& Tourism Research, 31(4), 431-454. doi:10.1177/1096348007302352

Owens, B. P., \& Hekman, D. R. (2012). Modeling how to grow: an inductive examination of humble leader behaviors, contingencies, and outcomes. Academy of Management Journal, 55(4), 787-818. doi: 10.5465/amj.2010.0441

Owens, B. P., Johnson, M. D., \& Mitchell, T. R. (2013). Expressed humility in organizations: Implications for performance, teams, and leadership. Organization Science, 24(5), 1517-1538. doi: 10.1287/orsc.1120.0795

Owens, B. P., Rowatt, W. C., \& Wilkins, A. L. (2012). Exploring the relevance and implications of humility in organizations. In G. M. Spreitzer \& K. S. Cameron (Eds.), The oxford handbook of positive organizational scholarship (pp. 260-272). New York: Oxford University Press.

Perry-Smith, J. E., \& Mannucci, P. V. (2017). From creativity to innovation: The social network drivers of the four phases of the idea journey. Academy of Management Review, 42(1), 53-79. doi:10.5465/amr.2014.0462

Peters, A. S., Rowat, W. C., \& Johnson, M. K. (2011). Associations between dispositional humility and social relationship quality. Psychology, 2(3), 155-161. doi: 10.4236/psych.2011.23025

Peterson, C., \& Seligman, M. (2004). Character strengths and virtues: $A$ handbook and classification. New York: Oxford University Press.

Podsakoff, P. M., MacKenzie, S. B., \& Podsakoff, N. P. (2012). Sources of method bias in social science research and recommendations on how to control it. Annual review of psychology, 63, 539-569. doi: 10.1146/annurevpsych-120710-100452

Podsakoff, P. M., MacKenzie, S. B., Lee, J.-Y., \& Podsakoff, N. P. (2003). Common method biases in behavioral research: a critical review of the literature and recommended remedies. Journal of Applied Psychology, 88(5), 879-903. doi: 10.1037/0021-9010.88.5.879

Priesemuth, M., Arnaud, A., \& Schminke, M. (2013). Bad behavior in groups: the impact of overall justice climate 
and functional dependence on counterproductive work behavior in work units. Group \& Organization Management, 38(2), 230-257. doi: 10.1177/1059601113479399

Quintane, E., Casselman, R. M., Reiche, B. S., \& Nylund, P. A. (2011). Innovation as a knowledge-based outcome. Journal of Knowledge Management, 15(6), 928-947. doi: 10.1108/13673271111179299

Ramamoorthy, N., Flood, P. C., Slattery, T., \& Sardessai, R. (2005). Determinants of innovative work behaviour: development and test of an integrated model. Creativity And Innovation Management, 14(2), 142-150. doi: 10.1111/j.1467-8691.2005.00334.x

Ramírez-Pasilla, M., Brundin, E., \& Markowska, M. (2017). Contextualizing entrepreneurship in emerging economies and developing countries. UK: Edward Elgar Publishing.

Rego, A., Owens, B., Yam, K. C., Bluhm, D., Cunha, M. P. e., Silard, A., ... Liu, W.(2017). Leader humility and team performance:exploring the mediating mechanisms of team psycap and task allocation effectiveness. Journal of Management. 45(3), 1009-1033. doi: 10.1177/0149206316688941

Rhoades, L., \& Eisenberger, R. (2002). Perceived organizational support: A review of the literature. Journal of Applied Psychology, 87(4), 698-714.doi:10.1037/00219010.87.4.698

Richards, N. (1992). Humility. Philadelphia, PA: Temple University Press.

Rousseeuw, P. J., \& Zomeren, B. C. van (1990). Unmasking multivariate outliers and leverage points. Journal of the American Statistical Association, 85(411), 633-639. doi: 10.1080/01621459.1990.10474920

Rowatt, W. C., Powers, C., Targhetta, V., Comer, J., Kennedy, S., \& Labouff, J. (2006). Development and initial validation of an implicit measure of humility relative to arrogance. The Journal of Positive Psychology, 1(4), 198-211. doi: 10.1080/17439760600885671

Rupp, D. E. (2011). An employee-centered model of organizational justice and social responsibility. Organizational Psychology Review, 1(1), 72-94. doi:10.1177/2041386610376255
Rutherford, G. S. W., \& Hair, J. F., Jr. (1988). Multivariate data analysis with readings. Journal of the Royal Statistical Society. Series D (The Statistician), 37(4/5), 484. doi: $10.2307 / 2348783$

Sarti, D. (2019). Balancing organizational justice and leader-member exchange to engage workforce: Evidence from social cooperatives in Italy. Journal of Workplace Learning, 31(3), 231-246. doi: 10.1108/jwl-09-2018-0116

Schilling, M. A. (2008). Strategic management of technological innovation. Boston: McGraw-Hill, Boston.

Schwarz, N., \& Clore, G. L. (1983). Mood, misattribution, and judgments of well-being: Informative and directive functions of affective states. Journal of Personality and Social Psychology, 45(3), 513-523. doi:10.1037/0022-3514.45.3.513

Scott, S. G., \& Bruce, R. A. (1994). Determinants of innovative behavior: A path model of individual innovation in the workplace. Academy of Management Journal, 37(3), 580-607. doi: 10.5465/256701

Seers, A., McGee, G. W., Serey, T. T., \& Graen, G. B. (1983). The interaction of job stress and social support: A strong inference investigation. Academy of Management Journal, 26(2), 273-284. doi: 10.5465/255975

Seijts, G., Crossan, M., \& Carleton, E. (2017). Embedding leader character into HR practices to achieve sustained excellence. Organizational Dynamics, 46(1), 30-39. doi: 10.1016/j.orgdyn.2017.02.001

Shalley, C. E., \& Gilson, L. L. (2004). What leaders need to know: a review of social and contextual factors that can foster or hinder creativity. The Leadership Quarterly, 15(1), 33-53. doi: 10.1016/j.leaqua.2003.12.004

Shapiro, D. L. (2001). The death of justice theory is likely if theorists neglect the "wheels" already invented and the voices of the injustice victims. Journal of Vocational Behavior, 58(2), 235-242. doi: 10.1006/jvbe.2001.1795

Sheehan, J. R. (2006). Understanding service sector innovation. Communications of the ACM, 49(7), 42-47. doi: $10.1145 / 1139922.1139946$

Spell, C. S., \& Arnold, T. (2007). An appraisal perspective of justice, structure, and job control as antecedents of 
psychological distress. Journal of Organizational Behavior, 28(6), 729-751. doi: 10.1002/job.441

Spence, M. (1973). Job market signaling. The Quarterly Journal of Economics, 87(3), 355-374. doi: 10.2307/1882010

Stinglhamber, F., \& Vandenberghe, C. (2003). Organizations and supervisors as sources of support and targets of commitment: A longitudinal study. Journal of Organizational Behavior, 24(3), 251-270. doi: 10.1002/job.192

Strobl, A., Niedermair, J., Matzler, K., \& Mussner, T. (2019). Triggering subordinate innovation behavior: The influence of leaders' dark personality traits and level 5 leadership behavior. International Journal of Innovation Management, 23(5), 1950045. doi: 10.1142/s1363919619500452

Suazo, M. M., Martínez, P. G., \& Sandoval, R. (2009). Creating psychological and legal contracts through human resource practices: A signaling theory perspective. Human Resource Management Review, 19(2), 154-166. doi: 10.1016/j.hrmr.2008.11.002

Tangney, J. P. (2000). Humility: Theoretical perspectives, empirical findings and directions for future research. Journal of Social and Clinical Psychology, 19(1), 70-82. doi: $10.1521 /$ jscp.2000.19.1.70

Teoh, K. R.-H., Coyne, I., Devonish, D., Leather, P., \& Zarola, A. (2016). The interaction between supportive and unsupportive manager behaviors on employee work attitudes. Personnel Review, 45(6), 1386-1402. doi: 10.1108/pr-05-2015-0136

Thakur, R., \& Hale, D. (2013). Service innovation: A comparative study of U. S. and Indian service firms. Journal of Business Research, 66(8), 1108-1123. doi: 10.1016/j. jbusres.2012.03.007

Tjosvold, D., Law, K. S., \& Sun, H. F. (2003). Collectivistic and individualistic values: Their effects on group dynamics and productivity in China. Group Decision and Negotiation, 12(3), 243-263. doi: 10.1023/a:1023383200180

Triandis, H. C. (2001). Individualism-collectivism and personality. Journal of Personality, 69(6), 907-924. doi:10.1111/1467-6494.696169

Unterhitzenberger, C., \& Bryde, D. J. (2018). Organizational justice, project performance, and the mediating effects of key success factors. Project Management Journal, 50(1), 57-70. doi: 10.1177/8756972818808984

Vera, D., \& Rodriguez-Lopez, A. (2004). Strategic virtues: Humility as a source of competitive advantage. Organizational Dynamics, 33(4), 393-408. doi: 10.1016/j. orgdyn.2004.09.006

Wang, D. C., Hall, M. E. L., Shannonhouse, L. R., Mize, M. C. B., Aten, J. D., Davis, E. B., ... Annan, $\mathrm{K}$. (in press). Why leader humility is vital to effective humanitarian aid leadership: A review of the literature. Disaster, 2020. doi: 10.1111/disa.12446

Wang, J., Zhang, Z., \& Jia, M. (2017). Understanding how leader humility enhances employee creativity:the roles of perspective taking and cognitive reappraisal. The Journal of Applied Behavioral Science, 53(1), 5-31. doi: 10.1177/0021886316678907

Wang, X., Li, H., \& Yin, H. (in press). Antecedents and Consequences of Creativity in Teams: When and How Leader Humility Promotes Performance via Team Creativity. The Journal of Creative Behavior, 2019. doi: 10.1002/jocb.410

Wang, Y., Liu, J., \& Zhu, Y. (2018). How does humble leadership promote follower creativity? The roles of psychological capital and growth need strength. Leadership \& Organization Development Journal, 39(4), 507-521. doi:10.1108/LODJ-03-2017-0069

Yang, K., Zhou, L., Wang, Z., Lin, C., \& Luo, Z. (2019). Humble leadership and innovative behaviour among Chinese nurses: The mediating role of work engagement. Journal of Nursing Management, 27(8), 1801-1808. doi: 10.1111/jonm.12879

Yiing, L. H., Ahmad, K. Z.(2009). The moderating effects of organizational culture on the relationships between leadership behaviour and organizational commitment and between organizational commitment and job satisfaction and performance. Leadership \& Organization Development Journal, 30(1), 53-86. doi: 10.1108/01437730910927106

Young, L. D. (2012). How to promote innovative behavior at work? The role of justice and support within organizations. The Journal of Creative Behavior, 46(3), 220-243. doi: 10.1002/jocb.15 
Yuan, F., \& Woodman, R. W. (2010). Innovative behavior in the workplace: The role of performance and image outcome expectations. Academy of Management Journal, 53(2), 323-342. doi: 10.5465/amj.2010.49388995

Zhang, X., \& Bartol, K. M. (2010). Linking empowering leadership and employee creativity: the influence of psychological empowerment, intrinsic motivation, and creative process engagement. Academy of Management Journal, 53(1), 107-128. doi: 10.5465/amj.2010.48037118
Zhang, Y., \& Wiersema, M. F. (2009). Stock market reaction to $\mathrm{CEO}$ certification: the signaling role of CEO background. Strategic Management Journal, 30(7), 693710. doi: $10.1002 / \mathrm{smj} .772$

Zhou, F., \& Wu, Y. J. (2018). How humble leadership fosters employee innovation behavior: A two-way perspective on the leader-employee interaction. Leadership \& Organization Development Journal, 39(3), 375-387. doi: 10.1108/LODJ-07-2017-0181 


\section{Appendix - Scale Used}

\begin{tabular}{|c|c|c|}
\hline Factor name & Items coding & Items \\
\hline \multirow{5}{*}{$\begin{array}{l}\text { Service Employees' Innovative } \\
\text { Behavior (SEIB) }\end{array}$} & SEIB1 & I come up with innovative and creative ideas. \\
\hline & SEIB2 & I try to propose my own creative ideas and convince others/customers. \\
\hline & SEIB3 & I seek new service techniques, methods, or skills. \\
\hline & SEIB 4 & I provide suitable plans for developing new ideas. \\
\hline & SEIB5 & Overall, I consider myself to be a creative member of this firm. \\
\hline \multirow[t]{6}{*}{ Organizational Justice (OJ) } & OJ1 & Overall, I 'm treated fairly by my organization. \\
\hline & $\mathrm{OJ} 2$ & In general, I can count on this organization to be fair. \\
\hline & $\mathrm{OJ} 3$ & In general, the treatment I receive around here is fair. \\
\hline & OJ4 & Usually, the way things work in this organization are not fair. \\
\hline & OJ5 & For the most part, this organization treats its employees fairly. \\
\hline & OJ6 & Most of the people who work here would say they are often treated unfairly. \\
\hline \multirow[t]{9}{*}{ Leader Humility (LH) } & LH1 & My manager actively seeks feedback, even if it is critical. \\
\hline & LH2 & My manager admits when he or she doesn't know how to do something. \\
\hline & LH3 & $\begin{array}{l}\text { My manager acknowledges when others have more knowledge and skills } \\
\text { than him or her. }\end{array}$ \\
\hline & LH4 & My manager takes notice of others' strengths. \\
\hline & LH5 & My manager often compliments others on their strengths. \\
\hline & LH6 & My manager shows appreciation for the unique contributions of others. \\
\hline & LH7 & My manager shows a willingness to learn from others. \\
\hline & LH8 & My manager shows he or she is open to the advice of others. \\
\hline & LH9 & My manager shows he or she is open to the ideas of others. \\
\hline
\end{tabular}




\section{Financial support:}

The National Natural Science Foundation of China (grant numbers 71472055 and 71272175) and the National Social

Science Foundation of China (grant number 16AZD0006) supported this work.

\section{Conflicts of interest:}

The authors have no conflict of interest to declare

\section{Copyrights:}

RBGN owns the copyrights of this published content

\section{Plagiarism analysis}

RBGN performs plagiarism analysis on all its articles at the time of submission and after approval of the manuscript using the iThenticate tool.

\section{Authors:}

1. Wasim Abbas, Ph.D. Candidate, Harbin Institute of Technology, Harbin, China.

E-mail: Wasimabbas0092@outlook.com

2. Weiwei Wu, Ph.D. Business Administration, Harbin Institute of Technology, Harbin, China.

E-mail: wuweiwei@hit.edu.cn

\section{Authors' Contributions}

1. Wasim Abbas: Definition of research problem, Development of hypotheses or research questions (empirical studies), Development of theoretical propositions (theoretical Work), Theoretical foundation/ Literature review, Definition of methodological procedures, Data collection, Statistical analysis, Analysis and interpretation of data, Critical revision of the manuscript, Manuscript Writing.

2. Weiwei Wu: Definition of research problem, Development of hypotheses or research questions (empirical studies), Critical revision of the manuscript, Supervision. 